\title{
LOS BAÑOS DE MULA (MURCIA): UN ENTORNO RURAL EN DECLIVE. PROPUESTAS PATRIMONIALES Y DIDÁCTICAS
}

\author{
José Antonio López Fernández* \\ Universidad de Córdoba \\ Gregorio Canales Martínez** \\ $M^{a}$ Isabel Vera Muñoz*** \\ Universidad de Alicante
}

\section{RESUMEN}

El entorno rural de Los Baños, pedanía del municipio de Mula (Región de Murcia) presenta un claro declive demográfico y económico. Uno de los principales factores de este proceso reside en la escasa actualización del uso de sus aguas termales, dispuestas tradicionalmente en paradores y casas de baños de forma independiente. Sin embargo, la singularidad patrimonial de su arquitectura urbana e hidráulica, los recursos arqueológicos y naturales que circundan el área, además de la importancia actual del turismo de salud, son aspectos a tener en cuenta en la promoción y desarrollo de este territorio. En este trabajo se proponen una serie de actuaciones que podrían mejorar notablemente la situación social y económica de este paraje tan atractivo y único.

Palabras clave: Balneario; Patrimonio hidráulico; Desarrollo rural; Ruta turística; Centro de interpretación.

Recibido: 27 de julio de 2016

Devuelto para su revisión: 7 de noviembre de 2016

Aceptado: 20 de febrero de 2017

Departamento de las Ciencias Sociales y Experimentales. Universidad de Córdoba. Avda. San Alberto Magno, s/n. 14004 CÓRDOBA (España).E-mail: jalopez@uco.es

Departamento de Geografía Humana. Universidad de Alicante.E-mail: gregorio.canales@ua.es

Departamento de Didáctica General y Didácticas Específicas. Universidad de Alicante. E-mail: vera@ua.es 


\title{
Los Baños de Mula (Murcia): A rural environment in decline. Economic and educatio- nal proposals
}

\begin{abstract}
The rural setting of Los Banos, in the municipality of Mula (Murcia) presents a clear demographic and economic decline. One of the main causes of this process is the scarce update of its hot springs' use, which traditionally were arranged in hostels and bathhouses independently. However, the uniqueness of its urban heritage and hydraulic architecture, archaeological and natural resources of the surrounding area and the current importance of health tourism are aspects to consider in the promotion and development of this territory. This paper presents a series of actions that could significantly improve the social and economic situation of this place so attractive and unique.
\end{abstract}

Keywords: Los Baños de Mula, Heritage; Rural development; Improvement proposals.

\section{INTRODUCCIÓN: TERMALISMO Y TURISMO}

El uso de las aguas termales, que en su día se erigió fundamentalmente como un recurso terapéutico (Jarrassé, 2002), subordinado por los condicionamientos geofísicos de los manantiales en función de su localización (Lillo y Lisón, 2002), constituye en la actualidad una opción claramente turística, adaptada a las vigentes demandas sociales (Lillo, 2005; Lillo y Hernández, 2007). La mayor parte de los establecimientos balnearios ofrecen a día de hoy amplios paquetes de servicios formados por programas de salud, a los que se suman numerosas posibilidades de ocio en relación con la naturaleza, así como, la introducción de nuevas técnicas y tratamientos no vinculados propiamente a las características de las aguas (Larrubia y Luque, 2002); opciones que pretenden captar una tipología de viajeros en busca de ambientes más sosegados, menos masificados y en contacto con los espacios naturales. Aspectos éstos que, en ocasiones, se complementan con otros como son la búsqueda del bienestar psicológico, el culto al cuerpo, el hedonismo o el puro ocio (Lopes, 2005).

En la Región de Murcia, situada al Sureste de España, el turismo de salud es un eje bien consolidado en los balnearios de Archena y Fortuna (Lillo y Lisón, 2003, 2002). Sin embargo, Los Baños de Mula, que cuenta igualmente con la presencia de aguas mineromedicinales y una actividad de crenoterapia tradicional, no ha alcanzado el mismo desarrollo. Es compartida la opinión con Millán (2004), que sugiere un plan de actuación para dinamizar este lugar, pues aunque el enclave ofrece notables diferencias con relación a los anteriores, podría "actuar como factor de atracción para esta tipología de turistas o bien como el complemento idóneo para productos ya existentes, porque no cabe duda de que cada vez es mayor el número de personas que eligen el turismo de salud y belleza como alternativa" (Millan, 2004: 142).

La finalidad de este estudio ha sido constatar la situación actual que presenta la pedanía de Los Baños de Mula, en el centro geográfico de la Región de Murcia, donde desde tiempo inmemorial se han utilizado con fines terapéuticos y agrícolas las aguas de una fuente termal. Entre los objetivos particulares destaca el análisis de las características 
geofísicas y urbanas del enclave, la distribución tradicional de sus aguas, así como la evolución que ha tenido en los últimos años la oferta de alojamiento, lo cual nos proporcionará una visión temporal de su desarrollo. La metodología de trabajo utilizada consiste en un análisis geográfico de ámbito local, con amplia labor de campo y visitas al lugar para comprobar las particularidades que ofrecen los tradicionales paradores y casas de baño. Se han realizado entrevistas a los gerentes de los establecimientos que están en funcionamiento, así como a otros vecinos que habitan en el territorio. Todo ello completado con la revisión bibliográfica sobre diferentes cuestiones centradas en: los aspectos arqueológicos y/o geológicos de gran importancia en el área; los trabajos descriptivos del espacio urbano tanto recientes como históricos; y, por último, los proyectos y planes de dinamización realizados por la administración y centrados en la planificación de las vías de acceso, la protección de edificios singulares y la posible actualización de la oferta turística a finales del siglo XX. Igualmente, ha sido interesante la búsqueda de documentos relacionados con el área, centrada básicamente en el Archivo Municipal de Mula que, aunque no es muy abundante, aportan datos relevantes que dan respuesta a varias cuestiones sobre la propiedad de los edificios y la distribución de las aguas, vigentes en la actualidad. Con esta información, se plantean propuestas de mejora para la conservación de los inmuebles y aumento de su rentabilidad, incorporando nuevas funciones que ofrece el entorno.

\section{LOS BAÑOS TERMALES DE MULA, UN ENCLAVE SINGULAR EN EL INTERIOR DE LA REGIÓN DE MURCIA}

La Región de Murcia, al igual que ocurre en otros territorios del litoral Mediterráneo, se caracteriza por el predominio de un modelo de sol y playa, consolidado en torno al Mar Menor. Ha sido en las últimas décadas cuando se ha desarrollado, en virtud de la diversidad de recursos que posee, el denominado turismo de interior ${ }^{l}$. Éste descansa en el atractivo de su medio natural y rural, al ofrecer paisajes contrastados que combinan unidades de relieve que sobrepasan los 1.500 metros de altitud y espesas masas forestales, con espacios de cuencas sedimentarias donde conviven regadíos tradicionales con nuevos espacios modernizados, fruto de los avances tecnológicos que producen los nuevos sistemas de captación y distribución de agua (Gómez, López y Montaner, 2011). En este entorno sobresalen destacados núcleos urbanos con una riqueza patrimonial de primer orden que refuerzan el producto turístico que hoy en día se oferta. El mismo se basa en tres pilares fundamentales relacionados con la cultura, la religión y la salud; el primero encuentra su máximo exponente en las ciudades de Murcia, Cartagena y Lorca, donde al legado monumental construido se le suma en los últimos años, la puesta en valor de yacimientos arqueológicos de gran importancia debido a la riqueza de los descubrimientos, y que han sido musealizados con gran acierto; el segundo tiene su polo de atracción en Caravaca de la Cruz, convertida desde principios del siglo XXI en lugar santo del orbe católico; y por último, el tercero se localiza en los núcleos de Archena y Fortuna, cuyas instalaciones termales se mantienen en explotación desde época romana (Lillo y Lisón, 2003 y 2002).

1 La demanda turística en la Región de Murcia. Verano de 2014. Instituto de Turismo de la Región de Murcia, Consejería de Industria, Turismo, Empresa e Innovación. 


\section{Figura 1}

\section{LOCALIZACIÓN DE LOS BAÑOS DE MULA, REGIÓN DE MURCIA}

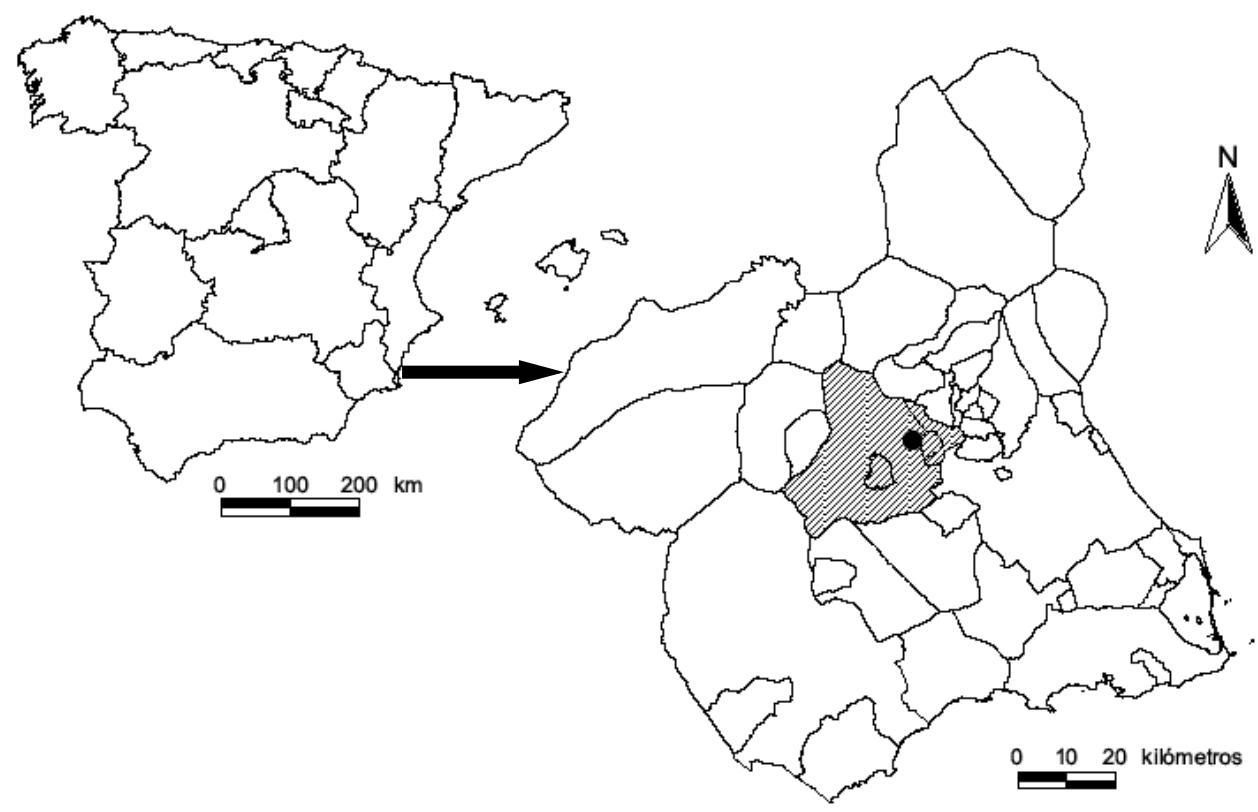

En rayado, los municipios que forman la comarca de Mula y el punto indica la localización del balneario (elaboración propia).

Uno de esos municipios, situado en el centro geográfico de la comunidad autónoma, y que a la vez da nombre a su propia comarca es Mula (Figura 1); población que reúne las tres variables que caracterizan el turismo de interior murciano, si bien con una proyección más reducida dado que su área de influencia no es tan amplia como en los casos anteriores; aunque la relevancia de su patrimonio bien podría convertirse en un importante factor de dinamización si se creyera en él y se trabajara de una forma integral, pues a la riqueza cultural hay que sumar un entorno natural atractivo, que desde el punto de vista turístico, no se ha comercializado conjuntamente. En una primera aproximación, la demarcación muleña alberga unos recursos extraordinarios para situarla en el mercado tanto nacional como internacional. Estos se relacionan con el:

- Turismo cultural. Mula es una fundación árabe ubicada en la ladera sur del Cerro del Cabezo, rematado por el actual Castillo de Los Vélez, sobre la antigua alcazaba musulmana que al igual que el núcleo primigenio, conoció una sustitución de sus mezquitas por templos cristianos en un callejero de trazado irregular (González, 1992). La expansión urbana se produjo en el siglo XVIII ocupando el piedemonte, con un urbanismo más regular en el que destacan notables conventos y casonas señoriales, conformando un centro histórico protegido como Bien de Interés Cultural (BIC). En él sobresale el Museo de Arte Ibérico de El Cigarralejo, ubicado en el antiguo palacio de Menahermosa y que 
expone una de las mejores colecciones de cultura material de ese periodo. Fuera del casco urbano destaca la Villa Romana de Los Villaricos, situada a escasos kilómetros del núcleo actual de Mula, en la carretera que va al embalse de La Cierva, conjunto arqueológico de los siglos III y IV d. C., que agrupa un espacio doméstico con área termal, además de otro económico dedicado a la producción de vino y, sobre todo de aceite, con una almazara recientemente descubierta que contaba con cuatro prensas, erigiéndose en una de las mayores industrias de este tipo halladas en la Península Ibérica; el conjunto arqueológico también cuenta con una pequeña basílica, además de una necrópolis con cincuenta fosas de enterramiento, testigo de los primeros cristianos en este territorio.

- Turismo religioso. En esta modalidad, destacan dos manifestaciones populares de diverso signo, vinculadas con el acervo de los habitantes; por un lado, la Semana Santa con un rico patrimonio imaginero, repuesto tras la Guerra Civil española, y que encuentra en el escultor Sánchez Lozano (García, 2017) su principal representante al seguir la estética dieciochesca de Francisco Salzillo. Si bien, es la tamborada de Mula el acto que tiene más proyección y congrega mayor número de seguidores, convirtiéndose en una seña específica de la localidad. El origen es incierto, aunque ya hay ordenanzas municipales de mediados del siglo XIX (González, 1994) que prohíben el uso del tambor fuera del horario convenido. En la actualidad, esta celebración está declarada de Interés Turístico Nacional, donde el miércoles santo se toca de forma ininterrumpida durante dieciséis horas, y ha dado lugar a una producción industrial de carácter artesanal en la fabricación del tambor. Por otro lado, el Santuario del Niño de Mula (González, 1995), edificación del siglo XVIII situada en el paraje rural del Balate, cuya veneración arranca del hecho milagroso acaecido tras la peste de 1648 en la persona del pastor Pedro Botía quien, al tomar los hábitos franciscanos y ser el confesor de Juan de Austria, propició que esta advocación se difundiera en la corte y alcanzara renombre internacional. En torno a su festividad, el 22 de septiembre, se organiza una romería que devuelve la imagen de nuevo al templo después de haber recorrido durante los días anteriores las diversas parroquias de la población.

- Turismo de salud. Es otra de las fortalezas que ofrece Mula de cara a su reclamo turístico, centralizado en la pedanía rural de Los Baños, pequeño caserío surgido al amparo de un manantial mineromedicinal cuyas primeras instalaciones constatadas para el uso sanitario de sus aguas se construyeron a lo largo del siglo XIX y primer tercio del XX, aunque su utilización pudo darse con anterioridad. Se trata de un enclave de indudable valor etnográfico, tanto por el patrimonio singular que allí se da, como por el conjunto arquitectónico que lo conforma, y que difiere de otros centros termales existentes en la región al carecer de una dirección médica centralizada y ofertar un alojamiento en viviendas o apartamentos -con poza individual para baño, mediante alquileres diarios o por horas- sin constituir un gran centro de salud al estilo de Fortuna y Archena. Este planteamiento dio lugar a un modelo de hábitat que ha llegado hasta nuestros días sin apenas modificaciones, ya que se mantienen las edificaciones primitivas, aunque, la falta de renovación ha originado en los últimos años el cierre de algunos inmuebles y los que perviven lo hacen en régimen de arrendamiento, circunstancia que contribuye a la escasa dinamización que se observa en el lugar, que no ha pasado de una utilización eminentemente familiar y local.

De los distintos recursos turísticos descritos someramente existentes en el municipio de Mula, es precisamente este último el que da cuerpo al presente trabajo. En él se 
aborda el inicio y la evolución de la actividad termal en el citado paraje rural, emplazado en un espacio natural atractivo que suma en sus inmediaciones otras potencialidades como la Vía Verde del Noroeste; los yacimientos romanos de La Almagra y Villaricos; la fortaleza islámica del Cerro de Alcalá y la ermita barroca de La Misericordia. De esta manera, el caserío de Los Baños de Mula se posiciona como un potencial núcleo de desarrollo dentro del turismo de interior de esta comunidad autónoma, que cuenta con la ventaja añadida de lo favorable de su emplazamiento con salida directa de la autovía que une Murcia con Caravaca de la Cruz (RM-15). Sin olvidar, la belleza de sus paisajes próximos, por cuanto allí conviven profundos tajos de cárcavas y tierras de badlans, con las huertas históricas que circunscriben el recorrido del río Mula, donde se puede encontrar un gran conjunto de patrimonio hidráulico (López, 2015), amén del emplazado en el citado balneario.

Sin embargo, la pedanía de Los Baños de Mula, a día de hoy, permanece dentro de ese norte deprimido, que diferenció Andrés Sarasa, al hablar de la dicotomía socioeconómica del territorio murciano, respecto al sur, más dinámico y próspero centrado en el Valle del Segura, el Guadalentín o el Campo de Cartagena (Andrés, 2000). En otros estudios de comarcalización, la demarcación de Mula se individualiza de la del Noroeste murciano (compuesta por los términos de Bullas, Calasparra, Caravaca de la Cruz, Cehegín y Moratalla), aunque presenta algunos caracteres territoriales parecidos. Como señaló Espejo (1997), se trata de una zona deprimida económicamente y condicionada por un progresivo despoblamiento debido a la falta de oportunidades; si bien en los últimos años, con el auge del turismo de interior, sobre todo de carácter religioso, y la puesta en marcha de la autovía RM-15, estos núcleos han presentado un leve crecimiento en su oferta turística, destaca Caravaca gracias a la devoción y promoción de la reliquia de la Vera Cruz. Por el contrario, la comarca de Mula (formada por el municipio homónimo, además de Albudeite, Campos del Río y Pliego) apenas participa de esta influencia, pese a ser la puerta de entrada desde la capital regional, y continúa un marcado proceso de vaciamiento demográfico y envejecimiento generalizado que concentra la población en el núcleo rector que le da nombre.

\section{EL USO TERMAL DEL AGUA Y LA GÉNESIS DE UN NÚCLEO HABITADO}

Las referencias documentales más antiguas que se tienen sobre la existencia de la surgencia de agua en el partido rural que en la actualidad se conoce como Los Baños, datan del siglo XIV cuando el adelantado de Murcia adquirió los dominios del Concejo de Mula donde se encontraba el manantial del marqués (González y González, 1996). No obstante, será en las primeras décadas del siglo XVIII cuando se posee una mayor información sobre la citada fuente, y se relaciona con los intereses desarrollados por Ginés Martínez Salazar, a la sazón alcalde de Mula, quien en 1720 obtuvo en posesión el agua y las tierras de este paraje, en un momento en el que se desconocían las virtudes salutíferas de estas emanaciones y no existía allí la menor alberqua, ni se hacía uso alguno de esos caudales. El nuevo propietario las destinó a la agricultura y, a la vez, las utilizó como fuerza motriz para dedicación industrial, construyendo un batán y molino harinero, que fueron las primeras edificaciones levantadas en la zona, en terrenos que anteriormente pertenecían a varios titulares al lograr "por título oneroso las que eran de 
particulares y por donación de la Excelentísima Señora Marquesa de los Vélez las que la pertenecían y aprovechamientos de la misma fuente del agua"2. A la muerte de Martínez Salazar, continuó disfrutando dicha propiedad su viuda Juana de Párraga, quien amplió algunas instalaciones con la construcción de varias casas y apeaderos de carruajes para los visitantes, lo cual induce a pensar que a lo largo de esa centuria ya se utilizaron con un propósito terapéutico.

En efecto, un siglo después ya tenemos constancia de la utilización de estas aguas con un fin sanitario, pues como recoge Pascual Madoz en su célebre obra "en el año de 1826, Don Rafael de Garfias, corregidor de Murcia, levantó una posada o parador con 19 habitaciones cómodas en su interior, y vistas al exterior muy deliciosas. El agua mineral entra y sale de las balsas que se han construido dentro de este edificio, en las que cómodamente se pueden bañar todos los que lo habitan. Posteriormente se ha construido otro parador con 12 habitaciones y dos balsas generales con las comodidades más indispensables" (Madoz, 1848). Con estos edificios empezó a desarrollarse el caserío de Los Baños, continuando el impulso constructor en la década siguiente, pues hay constancia de que José Estrada solicitó al Concejo de Mula en 1833 realizar nuevas obras junto al molino, a la vez que suplicaba igualmente la concesión de alguna parcela para edificar, pues en la petición se cita que hace límite con el inmueble que estaba realizando otro propietario, al indicar que se "le permita levantar edificios bajo el molino. Y también que se le haga merced del terreno que existe a la parte abajo lindando con las obras de José Raigal, el río y el camino que viene de la Misericordia"3. Alguna de estas construcciones debieron reedificarse con posterioridad al quedar arruinadas por las inundaciones del río Mula, que provocaron la destrucción de ciertos establecimientos, en concreto se cita la incidencia que la riada de Santa Brígida ocasionó al parador de El Intendente, del que se dice de forma pintoresca y alarmante que "fue arrancado de cuajo el 9 de octubre de 18344 y transportado por las aguas del río Mula hasta chocar con una gran roca, donde se partió y perecieron todos los bañistas" (González y González, 1996: 42).

De tal modo, se fue conformando un entramado urbano en torno al manantial mineromedicinal, cuyo desarrollo cronológico llega hasta mediados del siglo XX (Figura 2), ofreciendo una tipología constructiva propia, que mantiene el nombre primitivo de paradores; edificaciones que disponen de varias viviendas, con albercas que se distribuyen en el interior de cada una de ellas o se emplazan en la planta baja para un uso comunitario (Figura 3). Simultáneamente a la aparición de estos conjuntos, el caserío se amplió con la construcción de casas particulares unifamiliares o colectivas, algunas igualmente con disponibilidad de agua termal, y las que carecían de ella en su alojamiento, alquilaban por horas las infraestructuras del balneario El Pozo, conocido por el nombre de Baños Generales, complejo de piscinas que cumplían una función de servicio público. En el

2 Informe sobre la posesión de los Baños de Mula que hicieron varios regidores y diputados del Concejo de Mula el 29 de mayo de 1833 solicitado por D. José Estrada. Redactado por orden del Intendente de la Provincia de Murcia. Legajo 13, Tomo II del Archivo Municipal de Mula

3 Informe sobre la posesión de los Baños de Mula...op. cit. Legajo 13, Tomo II del Archivo Municipal de Mula.

4 Conocida como Riada de Santa Brígida, afectó a los principales ríos de la Provincia de Murcia: Segura, Guadalentín y Mula. En este último, provocó 27 víctimas mortales, casi todas en Los Baños ya que registró una subida del nivel del agua de 5 y 6 metros (Confederación Hidrográfica del Segura). 
Figura 2

ASPECTO ACTUAL DEL CONJUNTO TERMAL LOS BAÑOS DE MULA

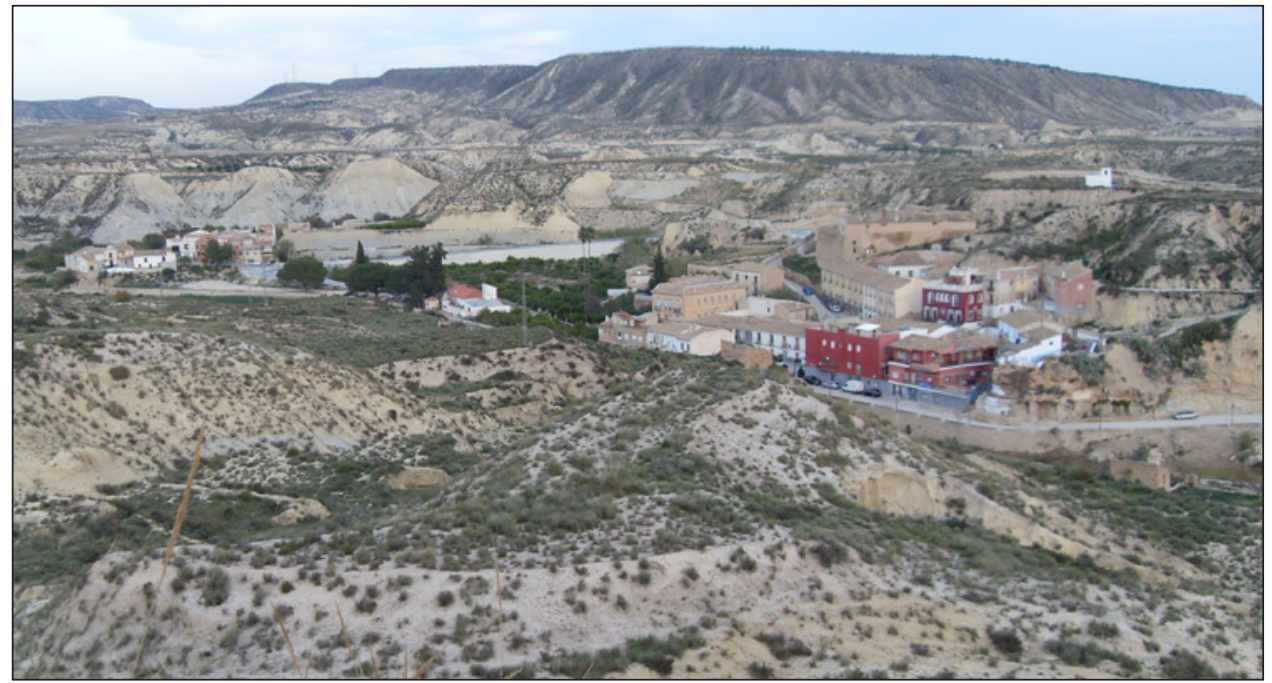

En la imagen el entorno rural de los baños, con el conjunto de paradores a la derecha y a la izquierda el Barrio de la Misericordia. Fotografía: J.A. López Fernández.

Figura 3

INTERIOR DEL PARADOR APARTAMENTOS AZUL

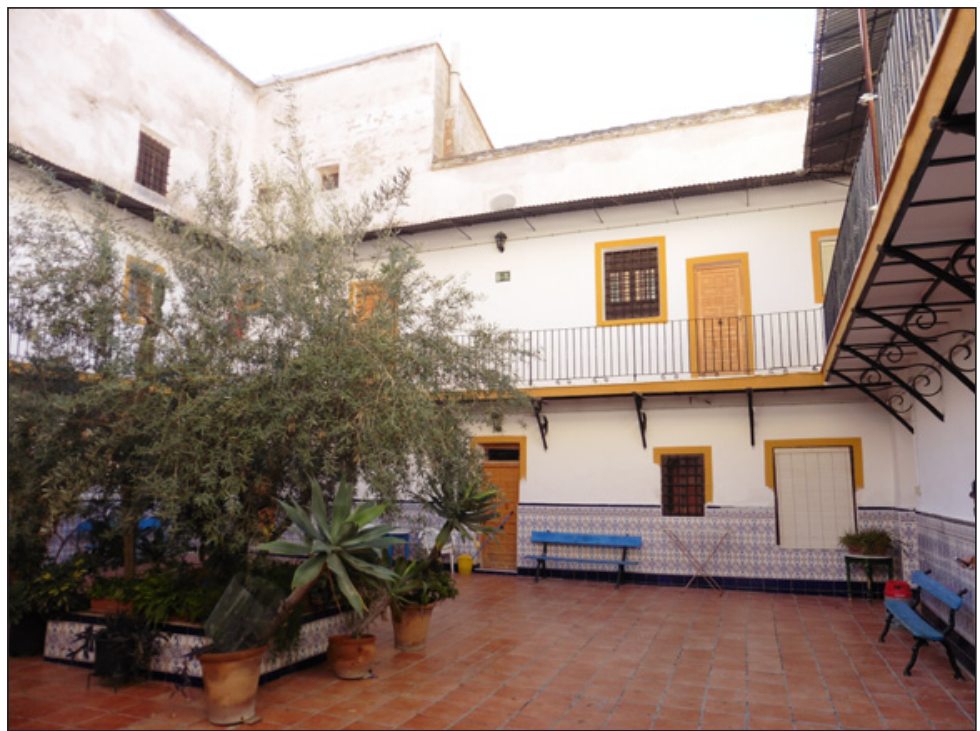

El inmueble organiza las habitaciones y salas termales alrededor de un patio central cuadrado. Fotografía: G. Canales Martínez. 
momento de máximo esplendor, en la década de los sesenta de la pasada centuria, el caserío mantenía abiertas diez instalaciones. Entre ellas, destacan los edificios de los Baños Modernos y la Casa de Baños o Parador de San Luis que, junto con la Ermita de La Misericordia, están catalogados según el Plan General del Ayuntamiento de Mula con el mayor nivel de protección patrimonial (BIC).

El conjunto de Los Baños está constituido por una agrupación de edificaciones dispuestas de forma discontinua en la margen derecha del río Mula, a lo largo de unos 500 metros, donde se observan tres unidades urbanas claramente diferenciadas. La primera, estaría formada por el complejo balneario, que ocupa la parte central de la pedanía, equidistante unos 250 metros de los otros dos enclaves. Se sitúa en el talud occidental de la meseta de Los Llanos, que cae al cauce del río, frente al cerro de La Almagra, donde se emplaza la fuente de la que parte un sistema de acequias para conducir los caudales a las diferentes viviendas. La estructura del callejero se ha organizado en torno al primitivo camino que serpentea la ladera para salvar el pronunciado desnivel y que ha dado origen a la aparición de dos calles a diferentes cotas, la inferior (calle Juan Martínez Soto) que es paralela al eje del río, y la superior (calle Cuesta del Horno) que asciende a la zona alta del talud. En ambas se ubicaron los paradores, mientras que por encima del manantial se construyeron casas destinadas a las familias que atendían las instalaciones termales.

La segunda, al norte, constituye el Barrio de La Misericordia, que toma el nombre de la ermita barroca construida en el siglo XVIII y que aglutina hoy en día un caserío formado por unas doce viviendas; entidad donde se levantó a principios de la centuria siguiente un hospicio, gracias a la acción benefactora llevada a cabo por un sacerdote muleño, destinado a personas sin recursos para que pudieran disfrutar del poder terapéutico de las aguas. La tercera, al sur, se emplaza fuera del valle del río y en la cima de la meseta, donde se hallan algunos inmuebles dispuestos de forma aislada, que surgieron al amparo de la carretera de Murcia a Caravaca de la Cruz, como son la Venta de la Magdalena y la antigua casa de postas Parador de Morata con varias viviendas anexas; también en esa zona se ubicó una casa de peones camineros, ya desaparecida, y unas escuelas que nunca entraron en funcionamiento, sobre las que actualmente se ha edificado un depósito de agua potable.

Las tres unidades descritas se articulan y quedan unidas por el eje viario tradicional, que parte de la carretera comarcal (C-415) que une Murcia con Caravaca. En 1933, con la puesta en funcionamiento de la línea férrea del Noroeste, se incrementaron los accesos al construirse, a través de la Misericordia, una vía con el apeadero "Baños de Mula", distante casi dos kilómetros del núcleo principal; a la vez que se trazó un nuevo carril desde donde hoy se sitúa el edificio de El Intendente, siguiendo el curso del río para remontar de forma más cómoda la ladera de la meseta sin tener que atravesar el conjunto edificado en dirección a Mula. El ferrocarril y la mejora de la accesibilidad están en la base del dinamismo que cobró la función termal hasta la década de los ochenta del siglo pasado. Con posterioridad, en 2005 se ha realizado al este del balneario y en paralelo, un nuevo ramal de comunicación que une la citada comarca con la barriada de la Misericordia; a pesar de esta actuación y las obras de mejora en parques y jardines, junto con la restauración fluvial del cauce, no se ha conseguido paralizar el progresivo decaimiento socioeconómico que en los últimos años presenta la actividad salutífera, marcada además por otros problemas que se describirán más adelante. 


\section{LA SINGULARIDAD DE LOS PARADORES Y CASAS DE BAÑO. EL USO INTEGRAL DEL AGUA}

Como se ha comentado anteriormente, la disposición caprichosa del núcleo urbano de Los Baños se presenta en la margen derecha del río Mula, en el escarpe que une el valle con la pequeña meseta de Los Llanos ${ }^{5}$. A través de la calle Juan Martínez Soto, paralela al cauce se puede acceder al balneario El Pozo (donde se emplaza el manantial de aguas termales), y los paradores de El Intendente, San Francisco, Baños Modernos, Apartamentos Azul y San Luis. Por encima de este conjunto, en la calle Cuesta del Horno, se llega a los establecimientos Baños Rita, El Delfín Rojo y de Molina, además de otra entrada a El Pozo. Entre ambas vías, en un pequeño callejón sin salida, se localiza el Parador de Domingo. De todos los negocios señalados, en la actualidad, sólo están en funcionamiento El Pozo, El Intendente, Apartamentos Azul y El Delfín Rojo (ver ubicación en Figura 4).

Figura 4

LOCALIZACIÓN DE PARADORES EN EL CASERÍO DE LOS BAÑOS (MULA)

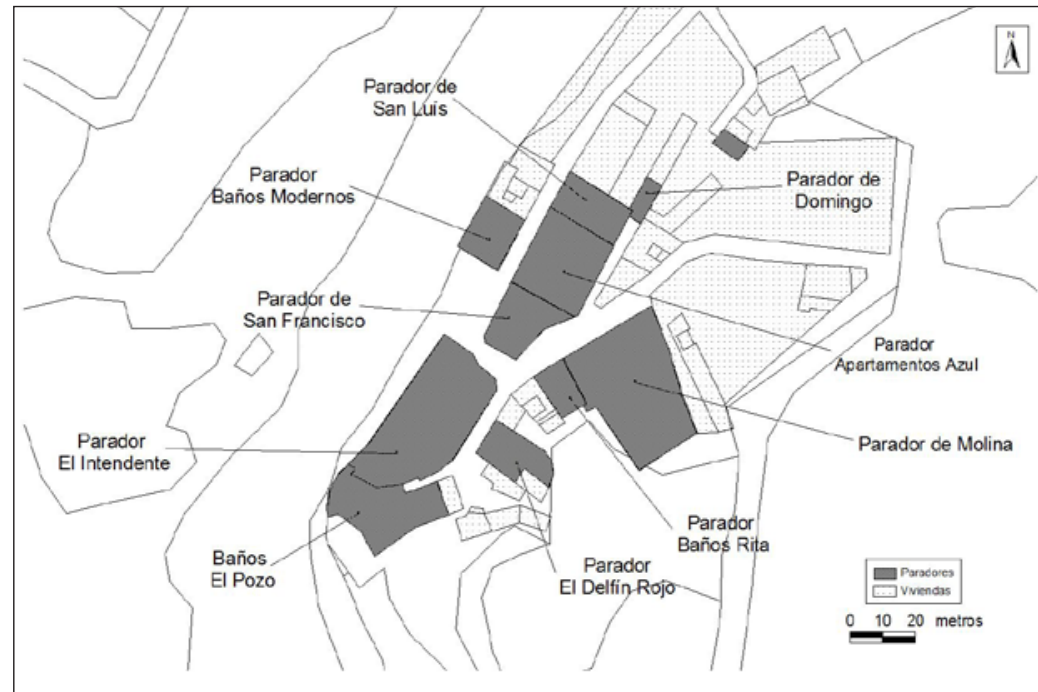

El núcleo central de Los Baños conforma el complejo termal cuyas instalaciones aparecen sombreadas en el mapa. Fuente: elaboración propia.

El balneario El Pozo, hoy en día, es una empresa que ofrece diferentes dependencias para el baño, sin embargo no ofrece servicio de alojamiento, al carecer de estancias de hospedaje. No obstante, su gran potencial estriba en el disfrute de las primeras aguas ema-

5 Los habitantes de este núcleo han vivido tradicionalmente de espaldas al río Mula. Mientras el manantial de aguas termales, génesis de la aldea, se ha utilizado tanto para el baño como el regadío, el cauce ha sido temido desde antaño, debido a las súbitas crecidas que han ocasionado inundaciones y destrozos en los inmuebles, e incluso la pérdida de vidas humanas. Al respecto, revisar la obra citada en la bibliografía de González Castaño (1996). 
nadas del manantial, las cuales se distribuyen en siete salas con piscina, cuya capacidad de uso varía desde dos hasta dieciséis personas (Figura 5). La totalidad de las albercas han sido reformadas recientemente, e incluso dos de ellas, disponen de servicio de hidromasaje que, junto con la apertura de un espacio habilitado para restauración, son las mejoras realizadas en los últimos años.

\section{Figura 5 \\ VISTA INTERIOR DE UNA DE LAS ALBERCAS TERMALES DE EL POZO}

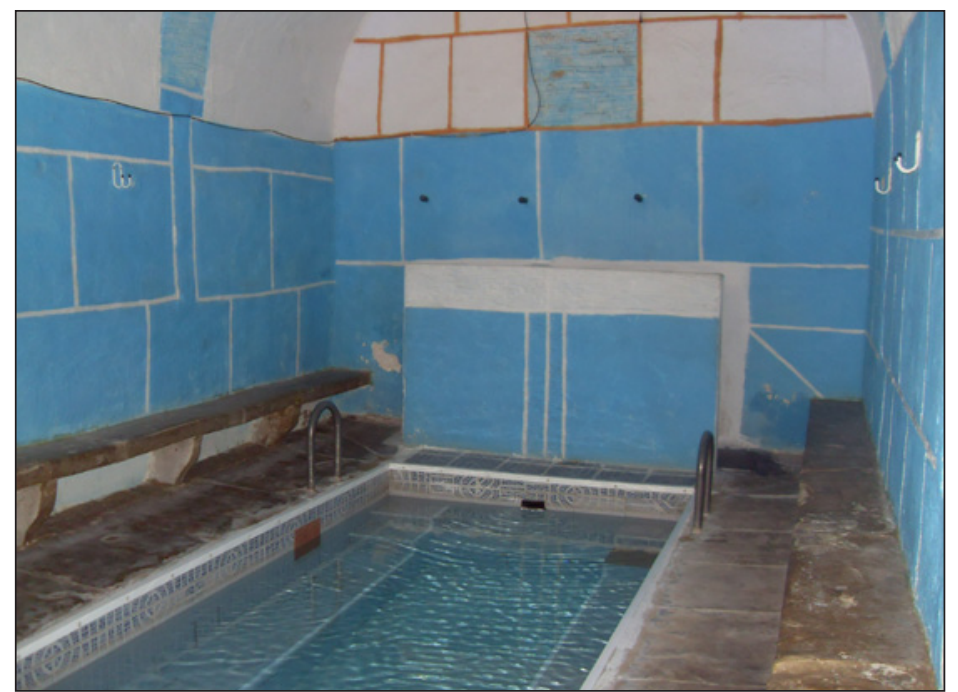

El establecimiento dispone de siete pozas, la imagen denota el paso del tiempo en la piscina de mayor tamaño. Fotografía: J.A. López Fernández.

Los otros centros hidrotermales abiertos al público son los paradores El Intendente, Apartamentos Azul (Figura 6) y El Delfín Rojo. Remozadas sus instalaciones, conservan el halo tradicional en su arquitectura de fachadas y en la distribución interior de sus aposentos. No obstante, a pesar de ofertar alojamientos en apartamentos y casas, el número de servicios se ha reducido desde que dio comienzo el nuevo siglo. Debido al declive en la demanda, los tres ofertan sus piscinas por horas cuando tienen las dependencias libres, pues el número de visitantes que antaño pasaban algunos días en el lugar ha descendido considerablemente. Las personas que pernoctan así como las que acuden únicamente a tomar los baños se concentran, sobre todo, en los periodos festivos de Semana Santa, Navidad y fiestas de septiembre de la capital comarcal.

En palabras del gerente de El Intendente "hace diez años había colas para bañarse, y eso ya no se produce". Entre las fechas señaladas, era tradicional venir a Los Baños en el día y noche de San Juan, pero en el último año, indicaba con pesadumbre "solo me han solicitado dos reservas". Respecto a los Apartamentos Azul, su arrendataria indica que sus alquileres no superan la centena al año, aunque especifica que son frecuentados por visitantes procedentes de diferentes provincias: Valencia, Barcelona, Alicante, Vizcaya, Álava 
e Vasco e incluso algunos provenientes de Francia. Se trata siempre de gente adulta y de la tercera edad, que acuden al lugar casi anualmente y que conocieron el establecimiento gracias a la información suministrada por terceras personas. El Delfín Rojo, al igual que el anterior, presenta una clientela reducida y variada en cuanto a su origen geográfico tanto nacional como extranjero. Esta instalación, que a principios de siglo XX se conocía por el nombre de Hotel Zapata, a diferencia de los anteriores, no presenta pozas de baños en los apartamentos, sino que solamente se disponen en la planta baja.

Un problema observado es que la gerencia de los paradores, a pesar de que cada día son menos los servicios que prestan, carecen de estadísticas fiables del número exacto de visitantes. Sin embargo, el conocimiento de estos datos, junto con las inquietudes, intereses y la recogida de la opinión personal, pueden servir a la hora de tomar decisiones para mejorar la oferta de estos negocios rurales. Solo los arrendatarios del balneario El Pozo ofrecen algunos de estos datos, así como el tipo de usuarios en los últimos años. Al respecto, entre 2016 y verano de 2017, esta marca registró una mayor demanda entre los meses de octubre a mayo, sobre todo en fines de semana (ochenta baños durante puentes y festivos) y fechas marcadas como San Valentín (sesenta baños), con precios que van, en función de la piscina alquilada, entre los doce y los veinticinco euros. Aunque reciben un número significativo de clientes que superan los sesenta años, también son frecuentados por un público más joven, gracias a la apertura reciente de un servicio de restauración y unas instalaciones que, modernizadas, higiénicas y acogedoras, consiguen mantener su aureola tradicional.

\section{Figura 6 \\ VISTA GENERAL DE LA CALLE JUAN MARTÍNEZ SOTO}

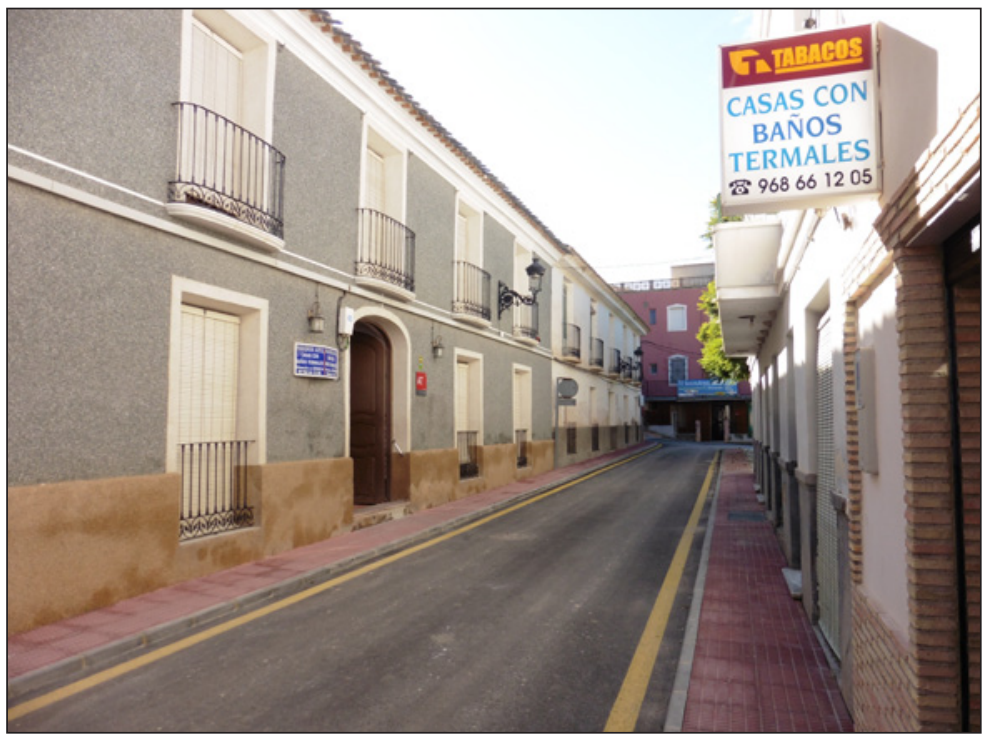

En la imagen, los paradores San Francisco y Apartamentos Azul a la izquierda, Baños Modernos a la derecha y El Intendente al fondo. Fotografía: G. Canales Martínez. 
Los paradores en uso disfrutan a día de hoy de la mayor parte de las participaciones del manantial, ya que se reparten proporcionalmente las acciones de agua correspondientes a los que ya han cerrado. A pesar de que casi el $70 \%$ de la propiedad de ésta, así como algunos edificios fueron adquiridos a principios de siglo XXI por la sociedad mercantil Nuevos Baños de Mula, cuyas intenciones constructivas y/o especulativas no llegaron a cristalizar. Sin embargo, la fuente nunca han dejado de manar (si bien conoció un descenso drástico cuando se produjo un sondeo cerca de la Sierra de Cejo Cortado, en las inmediaciones de Yéchar, que fue paralizado), sufre una merma en la actualidad debido a la demanda hídrica que requiere la puesta en riego de secanos próximos, situación que se ha hecho alarmante y que ha provocado la queja de los usuarios. En este sentido, los medios de comunicación recogían en noviembre de 2016 "que desde principios de siglo, y coincidiendo con los nuevos regadíos, el caudal que abastece a las casas de baños y a la agricultura tradicional ha descendido de 100 a 10 litros por segundo". De mantenerse esta disminución, Antonio Ortega, presidente de la Comunidad de Regantes Huerta de la Misericordia, exponía que es urgente encontrar una solución y alertó que "el pueblo y la huerta se pierde, mientras que unas multinacionales están sobreexplotando el secano" (LaVerdad.es).

Para la distribución del agua hacia los paradores, en la misma boca del pozo, construido en mampostería y con 16 metros de profundidad, existen dos tomas principales; una de ellas, a su vez se subdivide en dos ramales, llevando volúmenes directos a El Pozo y a El Intendente, mientras que la otra conduce el caudal hasta un partidor que presenta once secciones, aunque hoy solo tiene abiertas las salidas hacia El Delfín Rojo y Apartamentos Azul. Así, los recursos hídricos sirven para abastecer a los diferentes baños, distribuidos estratégicamente para aprovecharlos por gravedad. Una vez abastecidas las casas termales, pasan a un canal de desagüe con la intención de ser utilizados posteriormente en el regadío histórico que circunda el Barrio de La Misericordia. Antiguamente, la red de canalizaciones se prolongaba por la ribera del río y con ayuda de un sistema de norias salvaba los obstáculos físicos del terreno, hasta llegar a los pagos de los municipios de Albudeite y Campos del Río.

Las cualidades mineromedicinales son muy aceptables para su utilización sanitaria, con una temperatura en el momento de emanación de $37,3^{\circ} \mathrm{C}$ y una mineralización fuerte, sobre todo por el alto contenido de sulfatos $(817 \mathrm{mg} / \mathrm{l})$, calcio $(268 \mathrm{mg} / \mathrm{l})$ y sílice $(25,7$ $\mathrm{mg} / \mathrm{l}$ ), apropiadas según la tradición terapéutica para tratamientos de reuma, artrosis, piel y riñón (Paniagua y Martínez, 2003). Además, son señaladas sus propiedades en cuanto a problemas de fertilidad, aunque en este sentido el balneario destaca más por las numerosas anécdotas que se cuentan de carácter sexual provocadas por el fulgor de sus aguas (Galiana y Fernández, 1977).

La importancia de estos establecimientos, singulares en cuanto a su distribución y arquitectura, se recoge en el Estudio informativo de los Baños de Mula y propuestas para su promoción y desarrollo turístico realizado en 1993 con la participación del Ministerio de Comercio y Turismo, la Comunidad Autónoma de Murcia y el Ayuntamiento de Mula. La documentación ofrece la situación que presentaba el conjunto termal al aportar una ficha técnica para cada uno de los balnearios allí emplazados, confeccionada entre 1982 y 1992, con datos relevantes sobre el inicio de apertura, las plazas de alojamiento que poseían y las peculiaridades de los inmuebles, características éstas que quedan plasmadas en la Tabla 1, a excepción de El Pozo, ya que nunca contó con instalaciones de hospedaje. 
De la citada información conviene precisar las superficies de algunos de los apartamentos dedicados al alquiler, que varían de los 56 a los 81 metros cuadrados. Además, se induce por las fechas de construcción de estas dependencias, que el cuerpo urbano de Los Baños estuvo formado en su génesis por los paradores Apartamentos Azul y El Intendente. El primero conocido como Parador Viejo, debido a su antigüedad, finales del siglo XVIII, mientras que el segundo fue inaugurado en 1826, aunque la reedificación actual tuvo lugar de 1912 a 1914. El resto de construcciones se levantaron a comienzos del siglo XX, al igual que el Parador de San Luís (fechado en 1903), si bien éste de uso particular. Para esos años, ya se encontraban cerrados el Parador de Domingo y los Baños Rita; no obstante, estaba prevista la construcción de un hotel cuyas obras comenzaron durante esa centuria pero del que solo se llegó a construir la estructura, abandonándose el proyecto al poco tiempo, muestra evidente de la etapa de decadencia que ya se experimentaba en el lugar.

Tabla 1

ESTABLECIMIENTOS TERMALES EN LOS BAÑOS DE MULA EN 1993

\begin{tabular}{|l|c|c|c|}
\hline \multicolumn{1}{|c|}{ Parador } & Apartamentos & Plazas & Edificación actual \\
\hline El Intendente & 5 & 17 & $1912-1914$ \\
\hline Baños Modernos & 5 & 30 & 1900 \\
\hline El Delfin Rojo & 3 & 16 & 1925 \\
\hline Apartamentos Azul & 6 & 28 & Finales del siglo XVIII \\
\hline Parador San Francisco & 5 & 19 & 1900 \\
\hline Parador de Molina & 5 & 30 & No consta \\
\hline TOTAL & 29 & 140 & - \\
\hline
\end{tabular}

Fuente: Estudio informativo de los Baños de Mula y propuestas para su promoción y desarrollo turístico, Ayuntamiento de Mula.

En la actualidad, el caserío presenta un claro retroceso por el cierre de varios establecimientos ya que solo se encuentran en funcionamiento tres de los anteriores paradores reseñados, además de los baños El Pozo, tal y como consta en la Tabla 2. La evolución de la oferta de hospedaje en la pedanía se ha reducido notablemente entre 1993 y 2017 cuyo descenso se observa tanto en la capacidad de alojamiento (al disminuir el número de apartamentos de 29 a 18) como en el total de plazas (de 140 camas a 86), a pesar del esfuerzo realizado en los últimos años por algunos arrendatarios al introducir mejoras en sus dependencias e incluso ampliar el negocio. Se trata, en unos casos, de obras de mantenimiento y adecuación de las instalaciones a los nuevos tiempos, atendiendo sobre todo a la incorporación de hidromasajes y al revestido de las piscinas. Mientras que la construcción de nuevos apartamentos solo se ha practicado por El Intendente, al unir a su establecimiento un solar anexo donde en su día se emplazó un molino harinero y un batán; de esta forma ha aumentado significativamente su capacidad de acogida, pues de las cinco viviendas turísticas que poseía en 1993 se ha pasado a las nueve que dispone hoy en día, equipadas de uno a tres dormitorios. 
Tabla 2

ESTABLECIMIENTOS TERMALES EN LOS BAÑOS DE MULA EN 2017

\begin{tabular}{|l|c|c|c|}
\hline \multicolumn{1}{|c|}{ Parador } & Categoría (llaves) & N. $^{\mathbf{0}}$ Apartamentos & N. $^{\mathbf{0}}$ Plazas \\
\hline El Intendente & 1 & 9 & 40 \\
\hline Apartamentos Azul & 1 & 6 & 28 \\
\hline Delfín Rojo & 1 & 3 & 18 \\
\hline TOTAL & - & 18 & 86 \\
\hline
\end{tabular}

Fuente: Instituto de Turismo de la Región de Murcia.

Como se ha anotado anteriormente, uno de los factores que incide en el estancamiento actual, es el régimen de arrendamiento que presentan las instalaciones. Este problema afecta negativamente a la promoción como enclave de interés para el desarrollo turístico, ya que los gerentes actuales de los balnearios intentan sacar adelante el negocio, pero al realizarse bajo contratos de corta duración, resta posibilidades de inversión, al tratarse de acuerdos temporales que no van más allá de un lustro por lo que solo se efectúan trabajos de mantenimiento. Esta situación va en detrimento de la oferta por lo que se requieren medidas de diverso tipo que actualicen el atractivo visual de las pozas y baños termales y cambien la imagen impopular de carácter social que ha alcanzado en las últimas décadas (Caravaca, 1976; Galiana y Fernández, 1977). Sin olvidar, las repercusiones negativas que ha tenido la mejora de la red de carreteras y la industria del automóvil, que han reducido drásticamente el número de pernoctaciones, así como la incorporación en centros hoteleros de espacios dedicados a la relajación y tratamientos de belleza (spa), que entran en competencia con el que se analiza.

\section{SITUACIÓN ACTUAL Y PROPUESTAS DE MEJORA EN EL ENTORNO DE LOS BAÑOS DE MULA}

Los 54 vecinos registrados en 2016 en Los Baños, carecen de recursos suficientes para su dinamización turística, circunstancia que se traduce inexorablemente en la situación de semiabandono que presenta el lugar, debido sobre todo a su declive y escasa renovación (Figura 7). Los residentes, en edad laboral, tienen su ocupación en la cabecera comarcal, mientras que en la pedanía, las pocas instalaciones termales que todavía subsisten solo necesitan de la atención de unas familias y no de forma intensiva. La oferta de ocio se complementa con unos mínimos servicios de restauración, los que presta El Intendente y El Pozo, a los que se une el bar La Almagra y Venta Magdalena, ambos en los accesos al núcleo consolidado, que intentan resistir ante la reducida clientela. La otra actividad económica de la zona es la agricultura tradicional de regadío; ésta ocupa una superficie que apenas supera las cinco hectáreas, cubiertas mayoritariamente de cítricos que requieren de una mínima dedicación y que ejerce una población envejecida a tiempo parcial. Todos estos aspectos demandan un plan de actuación integral que aproveche todos los recursos del territorio, y donde se ejecuten propuestas encaminadas al desarrollo rural. 


\section{Figura 7 \\ VISTA PARCIAL DE LOS BAÑOS DESDE LA MESETA DE LOS LLANOS}

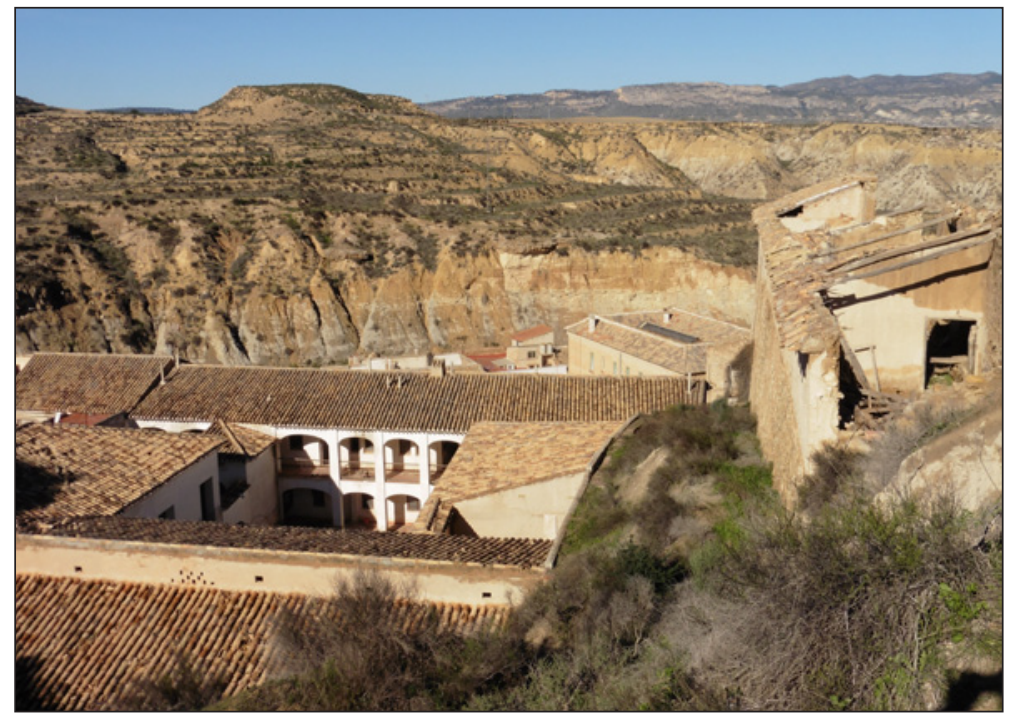

En primer término, abajo, el parador de Molina, cerrado en la actualidad. Puede observarse el deterioro de algunos inmuebles al abandonar su función. Fotografía: G. Canales Martínez.

En este sentido, sería de interés conservar la peculiaridad que presenta el enclave urbano formado por diferentes casas de baño, lo que constituye un modelo singular frente a los grandes complejos balnearios, pero dotándolo de mejores servicios y una adecuación exhaustiva de sus instalaciones, acondicionadas a los nuevos tiempos de ocio y salud, todo ello dentro de un paquete de promoción turística que englobe al conjunto de la comarca de Mula. Además, hay que incentivar y promover los recursos naturales y patrimoniales tan variados que circundan la pedanía (arqueológicos, etnográficos y geológicos, entre otros), con la intención de ofrecer un servicio capaz de captar nuevos visitantes, sobre todo los del entorno regional e incluso local (ya que resultan desconocidos para muchos residentes del municipio), con programas de posibles visitas guiadas que den a conocer el potencial territorial ignorado por una gran parte de la población autónoma. Igualmente, sería de interés la integración y difusión de la oferta, tanto en las oficinas turísticas públicas como en empresas privadas, que consigan divulgar las posibilidades que este lugar puede ofrecer a lo largo de todo el año, y romper así con la marcada estacionalidad.

Analizada la génesis y evolución de este espacio que, desde sus inicios ha mostrado una dependencia relacionada con el turismo de salud y donde el balneario ha sido su principal razón de ser, se señalan a continuación posibles líneas de actuación que, además de proyectar la importancia que posee el conjunto urbano y su entorno, ejerzan como motor económico de cara al futuro. Estas propuestas, gestionadas de forma globalizada, pueden contribuir a dinamizar este pequeño núcleo, salvándolo del deterioro físico, y su consecuencia más nefasta el vacío demográfico y el envejecimiento que muestra buena parte de 
los inmuebles, para convertirlo en un lugar turístico atractivo dentro del municipio. Tras el trabajo de campo realizado y las entrevistas con lugareños y gerentes de las instalaciones balnearias, se plantean algunas ideas relacionadas sobre todo con el uso del agua, así como con el patrimonio natural y cultural; todo ello desde una perspectiva del desarrollo local sostenible, al que se le deben sumar las posibilidades didácticas y educativas que ofrece el territorio.

a) Construcción o adecuación de un espacio como Centro de Interpretación. El entorno donde se ubica el conjunto urbano de Los Baños ofrece importantes recursos relacionados con el agua, ya sea por sus procesos erosivos o por el uso humano aplicado en diferentes actividades. Así, es de destacar el contraste paisajístico que se genera entre áreas semiáridas (con el dominio de suelos margosos y cultivos de secano) y los escasos pero productivos rincones de cítricos que conforman un corredor verde en torno al río Mula. Se trata de un área de gran valor medioambiental y cultural, donde sobresalen: la vegetación típica de la zona, de carácter xerófilo, adaptada a la indigencia de las lluvias; la presencia de margas coronadas en algunos puntos por cornisas de conglomerados o travertinos, como ocurre en la pequeña meseta de La Almagra o el Cerro de Alcalá; la existencia de restos arqueológicos de la cultura íbera en el cercano yacimiento de El Cigarralejo, romana en el de Villaricos y tardorromana en La Almagra; las ruinas del antiguo fortín islámico del Castillo de La Puebla; los tradicionales ingenios hidráulicos emplazados en el cauce fluvial para abastecer el regadío con norias y canalizaciones de derivación; y, por último, la propia configuración urbana del caserío, alrededor del manantial que posibilitó la dedicación balnearia. Aspectos estos que, de forma holística, constituyen la personalidad e identidad del territorio, dan sentido y sirven para fundamentar la creación de un Centro de Interpretación, que muestre el aprovechamiento económico y social que realizaron sus moradores durante siglos, cuyo mensaje sea lo más divulgativo posible para ampliar el conocimiento de la sociedad, tanto en el ámbito regional como para los visitantes foráneos.

El aprovechamiento hídrico en una región tan árida como la de Murcia, constituye un factor fundamental de vida y, por ende, de desarrollo. De ahí que Los Baños de Mula sean un exponente de la utilización secular que la sociedad ha realizado de un recurso que es escaso y, por consiguiente, sumamente valorado. Aspecto éste que se observa en el propio destino de las aguas termales, cuyo manantial situado a escasos metros del lecho del río, se ha caracterizado por mantener siempre una función comunitaria, que se expresa de forma diversificada. En primera instancia, abastecen a los balnearios sin que éstos puedan obstaculizar su fluir, beneficiándose tan solo de las propiedades terapéuticas; en segundo lugar, se reutilizan para la agricultura, dado que el canal de desagüe del complejo se convierte en acequia de riego en el cercano pago de La Misericordia; o se vierten al cauce, de donde vuelven a ser derivadas a través de sendos azudes para regar los parajes de Cara y Daya, entre los términos de Mula y Albudeite.

Por consiguiente, este caudal constituye un recurso fundamental para entender la ordenación del territorio, pues es la génesis de este paisaje, ya que su utilización condicionó la existencia de antiguos poblados cercanos como el de La Almagra, según se desprende de las investigaciones de otros autores (González, Fernández y Crespo, 1997). Solo así se puede comprender la disposición caprichosa del actual núcleo urbano, junto al río, lo que se traduce en un elevado riesgo y grado de vulnerabilidad debido a las 
crecidas que aquí se han producido. Este hecho se ha intentado mitigar en la última centuria con la construcción de un dique de contención de avenidas y, sobre todo, con el plan de protección integral de toda la cuenca a través de la disposición de embalses y presas de laminación. Si bien, aunque los daños no son tan significativos como en épocas pasadas, en cuanto a pérdida de vidas humanas, la pedanía sigue sufriendo inundaciones como las ocurridas en 1988, 2009 ó 2012, donde los perjuicios en las viviendas y en la agricultura fueron notables.

Una de las potencialidades del Centro de Interpretación radicaría en su importancia didáctica, orientada a las diferentes etapas educativas, desde los niveles básicos de primaria hasta la universidad; así como en la educación no formal. De este modo, el centro recibiría al visitante y serviría para introducir los hechos geográficos e históricos locales, relacionados con el agua y sus diferentes aplicaciones en un contexto amplio; todo ello inserto en un medio semiárido seccionado por un corredor verde generado por el río, donde se vinculan las huertas tradicionales y, más alejados, aparecen los nuevos espacios de regadío como ocurre en la cercana pedanía muleña de Yéchar (donde se pueden apreciar los resultados del proceso de concentración parcelaria llevado a cabo entre las décadas de 1960 a 1980, que ha motivado un paisaje de estructura geométrica opuesto al anterior), y a los que se puede acceder siguiendo la antigua vía férrea MurciaCaravaca, hoy transformada en Vía Verde del Noroeste.

Y es que el abordaje de la realidad espacial es fundamental en la formación educativa (Piñeiro, 1983). Como señala Marrón (1990: 162) es prioritario para incentivar un aprendizaje integral, pues plantea la comprensión “de la Geografía y de la Historia a partir del estudio del entorno mediante el análisis de cada uno de los elementos que le constituyen, para desembocar en una visión globalizadora de los hechos, es la forma más adecuada para despertar en los alumnos el interés por el conocimiento de la realidad múltiple y compleja que conforma el mundo actual". Ideas que no son nuevas, sino que fueron diseñadas y experimentadas por educadores como Pestalozzi, Dewey, Freinet o las hermanas Montessori durante el siglo XIX y principios del XX. Metodología que se desarrolló en España gracias a la Institución Libre de Enseñanza (Jiménez, 1984, 1996). Este lugar ha sido y es objeto de análisis por parte de algunos profesores universitarios en las salidas de campo que realizan con el alumnado, sobre todo en asignaturas pertenecientes al Grado de Geografía, donde se abordan conceptos de carácter natural que tienen que ver con la cuenca neógena, donde predominan los materiales margosos, la disposición de cerros testigos, los relieves en cuesta y los procesos de erosión remontante. Así como los de tipo cultural, relacionados con la disposición y aprovechamiento del territorio a partir de las escasas disponibilidades hídricas que han dejado como resultado la peculiaridad de los paisajes regados, tanto ancestrales como los transformados más recientemente; el variado patrimonio hidráulico con la presencia de numerosos ingenios de captación y distribución; y la presencia, por último, de un hábitat rural característico.

La valía del legado arquitectónico de la pedanía de Los Baños y la singularidad termal, son exponentes de un comportamiento social propio del siglo XIX, hoy ya superado, que pueden ser consideradas desde otros ámbitos como la Educación Primaria y la Secundaria. En virtud de los contenidos preceptivos actuales marcados por los currículos 
oficiales, el enclave puede servir para entender la importancia del agua en un territorio semiárido, sin olvidar la utilización integral que de la misma se ha hecho en la evolución del asentamiento, para cubrir las necesidades de abastecimiento tanto de tipo doméstico como aquellas otras que dieron origen a actividades económicas (agricultura, ganadería, industrias hidráulicas y aprovechamiento terapéutico) y generaron una peculiar ordenación del territorio. A ello, se pueden unir los diferentes vestigios arqueológicos encontrados en sus inmediaciones (íbero y romano fundamentalmente), cuya observación y análisis representaría un recurso vivencial, que puede favorecer y contribuir al proceso de aprendizaje del alumnado, a través de una metodología activa y participativa. El montaje expositivo del Centro de Interpretación debe mostrar un planteamiento holístico que aborde, además, otras cuestiones vinculadas al patrimonio inmaterial de la zona en relación con las costumbres, tradiciones y comportamientos de la sociedad que generó aquí una infraestructura de salud de carácter minoritario y a pequeña escala, bajo un concepto de explotación de tipo individual formado por la casa de huéspedes. Modelo alejado de los grandes negocios terapéuticos que surgieron también en esa misma época, con un planteamiento más moderno y capitalista, regentado por sociedades que ofrecían a su clientela un seguimiento médico. De esta forma, los discentes pueden dar sentido a muchos conceptos teóricos, al comparar ambos tipos de balneario y alcanzar conclusiones que les permitan emitir juicios de valor sobre las diferentes propuestas desarrolladas y su posterior utilización turística.

b) Creación de un itinerario natural-cultural. Los aspectos patrimoniales sintetizados de forma didáctica en el Centro de Interpretación, se deben complementar con la adecuación de un sendero que conecte los diversos lugares de interés y pongan al usuario en contacto directo con los elementos y peculiaridades del territorio. La propuesta que se ha diseñado para poner en valor la zona comenzaría al salir de la autovía RM-15 en el Mirador-aparcamiento que se ha acondicionado en la carretera comarcal (C-2) en dirección al caserío de Los Baños. Desde aquí, mediante una ruta de carácter circular, se atraviesa el conjunto termal y sin abandonar el citado eje viario en dirección a la pedanía de Yéchar, se pasa por el Barrio de La Misericordia, el puente sobre el río Mula, para llegar al antiguo Apeadero de Los Baños; donde se seguirá la Vía Verde del Noroeste hasta el Barranco del Corral; desde él por un camino de herradura se accede al Cerro de La Almagra para dirigirse de nuevo al balneario y desde allí, acceder al punto de partida.

El trazado tiene una longitud de algo más de cinco kilómetros, tal y como se muestra en la Tabla 3 y Figura 8, subdividido en ocho tramos donde se aprecia la amplia variedad de recursos endógenos que el territorio reúne. Entre ellos, se puede visualizar desde el punto de vista natural y de gran valor geomorfológico el conjunto de la Rambla de Perea, que desagua al río Mula en las inmediaciones del Barrio de La Misericordia, y está considerado Lugar de Interés Geológico debido, entre otros, a la presencia de enormes cárcavas fruto de los imponentes procesos de erosión remontante que se produce en los dominantes suelos margosos. Además, es frecuente encontrar (en ambos cauces) superficies con abundantes fósiles marinos e incluso arrecifes de coral, vestigios de la pretérita presencia marina. También resulta de interés observar la diversidad de especies vegetales, donde predomina la formación de un corredor de tarayales que convive con hábitats de agua dulce, formados por pastizales y juncales halófilos. 


\section{Figura 8 \\ ITINERARIO DIDÁCTICO PROPUESTO EN EL ENTORNO DE LOS BAÑOS DE MULA}

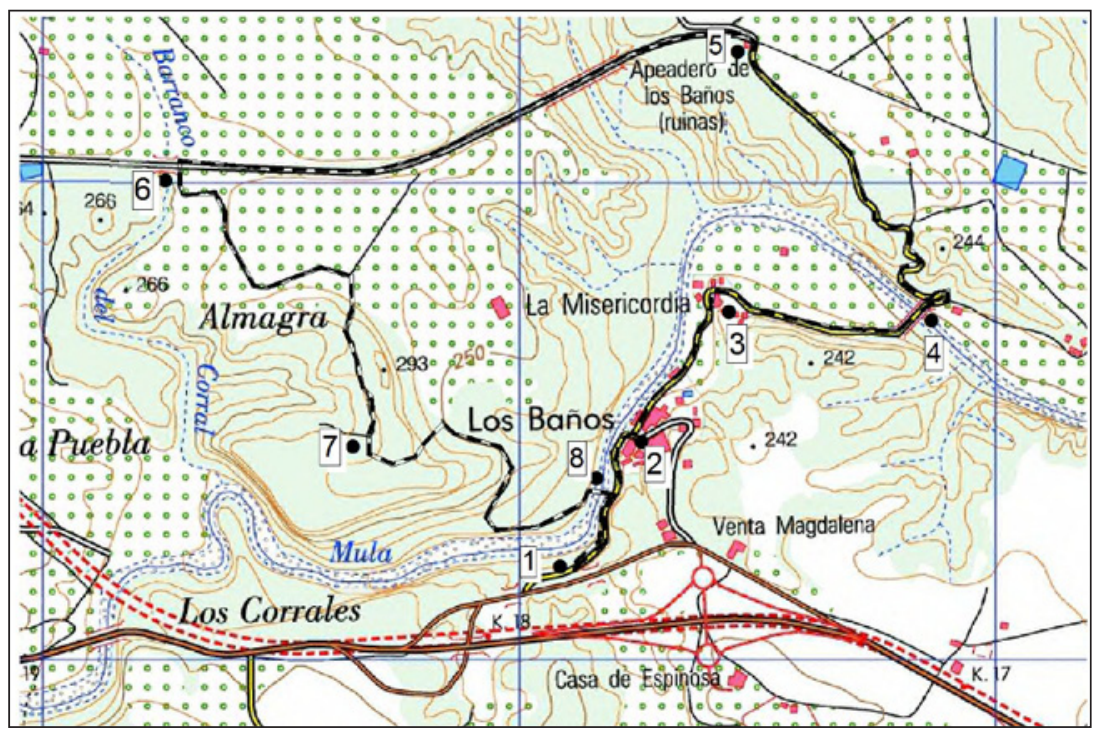

En el recorrido se puede disfrutar de la gran diversidad de valores naturales y culturales de este territorio del interior de la Región de Murcia. Fuente: elaboración propia.

Con relación a los bienes culturales es de destacar el yacimiento emplazado en el cerro de La Almagra (González y Fernández, 2002), que constituye a su vez, un mirador excepcional para contemplar la diversidad paisajística en cualquiera de las direcciones en las que se mire, configurada por la dicotomía entre los citados secanos y vegas fértiles, y en lontananza los relieves que cierran la comarca de Mula excepto por el Este, por donde se divisan las tierra del valle del Segura. El visitante podrá comprobar in situ el emplazamiento estratégico de lo que en su día fue el poblado que precedió a la Mula actual, y que numerosos investigadores aseguran ser una de las plazas firmantes en el Pacto de Tudmir a comienzos del siglo VIII (López, 1995; González y Fernández, 1997). Entre los restos excavados, se ha logrado identificar un edificio de culto, numerosas tumbas anexas a éste, así como los cimientos de la antigua muralla que rodeaba la aldea por tres de sus flancos, salvo por el Suroeste, que se protegía de forma natural por la existencia de un precipicio sobre el río.

En la actualidad presenta un estado de abandono considerable, pese a estar declarado Bien de Interés Cultural, por lo que sería deseable continuar con las labores arqueológicas para profundizar en el conocimiento de este antiguo poblado y la adecuación museográfica de dicho espacio para una mejor y más clara comprensión por los posibles visitantes. Más reciente, pero con un gran impacto visual y paisajístico, son las infraestructuras patrimoniales que conformaron en su día la vía férrea que unía Murcia con Caravaca, reconvertida en la actualidad como Vía Verde del Noroeste (Figuras 9 y 10). 
Tabla 3

ITINERARIO PROYECTADO PARA LA PUESTA EN VALOR DEL TERRITORIO

\begin{tabular}{|c|c|c|}
\hline TRAMO & DISTANCIA (m) & RECURSO DOMINANTE \\
\hline Mirador/aparcamiento (C-2) - Los Baños & 308,8 & Paisajístico - Arquitéctonico \\
\hline Los Baños - Barrio de La Misericordia & 419,4 & Termal - Patrimonial \\
\hline Barrio de La Misericordia - Puente del río Mula & 479,5 & Natural - Paisajístico \\
\hline Puente del río Mula - Apeadero Los Baños & 876,9 & Patrimonial - Ferroviario \\
\hline Apeadero Los Baños - Barranco del Corral & $1.254,3$ & Ferroviario - Agrícola \\
\hline Barranco del Corral - Cerro de La Almagra & 812,4 & Paisajístico - Arqueológico \\
\hline Cerro de La Almagra - Los Baños & 736,6 & Arqueológico - Fluvial \\
\hline Los Baños - Mirador/aparcamiento (C-2) & 308,8 & Museístico - Cultural \\
\hline TOTAL & $5.196,7$ & - \\
\hline
\end{tabular}

Elaboración propia a través del visor aéreo de la web de la Infraestructura de Datos Espaciales de la Región de Murcia (IDERM).

La ruta finaliza en el propio casco urbano de la pedanía que, por la importancia arquitectónica de algunos edificios, representa un hito de indudable valor patrimonial alejado de los patrones que marcaron los grandes complejos de salud del siglo XIX. El conjunto balneario se extiende por una superficie de $7.250 \mathrm{~m}^{2}$, mientras que el Barrio de La Misericordia ocupa $4.280 \mathrm{~m}^{2}$ aproximadamente. Entre los paradores están catalogados dos inmuebles dentro del inventario regional según la Ley 16/1985, de 25 de junio, de Patrimonio Histórico Español, presentes ahora en la Ley 4/2007 de Patrimonio Cultural de la Comunidad Autónoma de la Región de Murcia: la denominada Casa de Baños, edificada en 1903 en estilo neomudéjar y con elementos decorativos modernistas; así como los Baños Modernos, levantados unas décadas después y de carácter racionalista. En el segundo lugar tiene dicha categoría la Ermita de La Misericordia, edificio neoclásico de finales del XVIII, de planta rectangular (6,5 m de ancho por $14 \mathrm{~m}$ de profundidad) y bóveda de medio cañón con lunetos, dividida por falsos arcos fajones, que descansan sobre ménsulas molduradas en los muros laterales. Su fachada es de extrema sencillez, presenta cubierta a dos aguas y distribuye en el eje central tres vanos que se corresponden con la puerta, un ventanal superior y el hueco de la espadaña donde está instalada la campana.

Estas medidas administrativas resultan a todas luces insuficientes, al menos para la entidad que conforma el conjunto de casas de baño, por cuanto éste ha llegado hasta nuestros días conservando la esencia originaria, dado que su desarrollo quedó paralizado en el último cuarto del siglo $\mathrm{XX}$ ante el auge de los grandes negocios termales $\mathrm{y}$, sobre todo, por la consolidación del turismo en el litoral. A nuestro criterio, el entramado urbano debería contemplarse como un todo por los valores culturales que reúne, pues si se aplican las figuras de protección para los bienes inmuebles que contempla la citada normativa murciana, podría catalogarse como BIC en alguna de las siguientes modalidades: Monumento ("la construcción u obra producto de la actividad humana, de relevante interés histórico, arquitectónico..., etnográfico... o social, y que por sí sola constituya una unidad singular"); Conjunto Histórico ("la agrupación de bienes inmuebles que forman una unidad de asentamiento, continua 
o dispersa... por ser testimonio de su cultura o constituir un valor de uso y disfrute para la colectividad"); Sitio Histórico ("el lugar o paraje natural vinculado a acontecimientos o recuerdos del pasado, creaciones culturales... y a obras del hombre") y, por último, Lugar de Interés Etnográfico ("conjunto de construcciones o instalaciones vinculadas a formas de vida, cultura y actividades propias de la Región de Murcia”). De acuerdo con dicha ley, las cuatro categorías anteriores podrían tenerse en cuenta para declarar como BIC esta agrupación urbana. No obstante, este planteamiento proteccionista no ha contado con ningún apoyo social hasta el presente, al no existir reivindicación en este sentido, si bien, recientemente, ante el descenso experimentado en el caudal aflorado, han surgido voces críticas, tanto por los interesados de los establecimientos salutíferos, como por los integrantes de la Comunidad de Regantes de la Misericordia y los heredamientos dependientes de Albudeite y Campos del Río, en aras de lograr una solución a sus problemas. Demanda que aglutina intereses económicos de diverso tipo y que afecta a un mayor número de personas dado el predominio minifundista que se alcanza en el regadío histórico.

\section{Figura 9 \\ VIADUCTO DE LA ANTIGUA LÍNEA DEL FERROCARRIL MURCIA-CARAVACA}

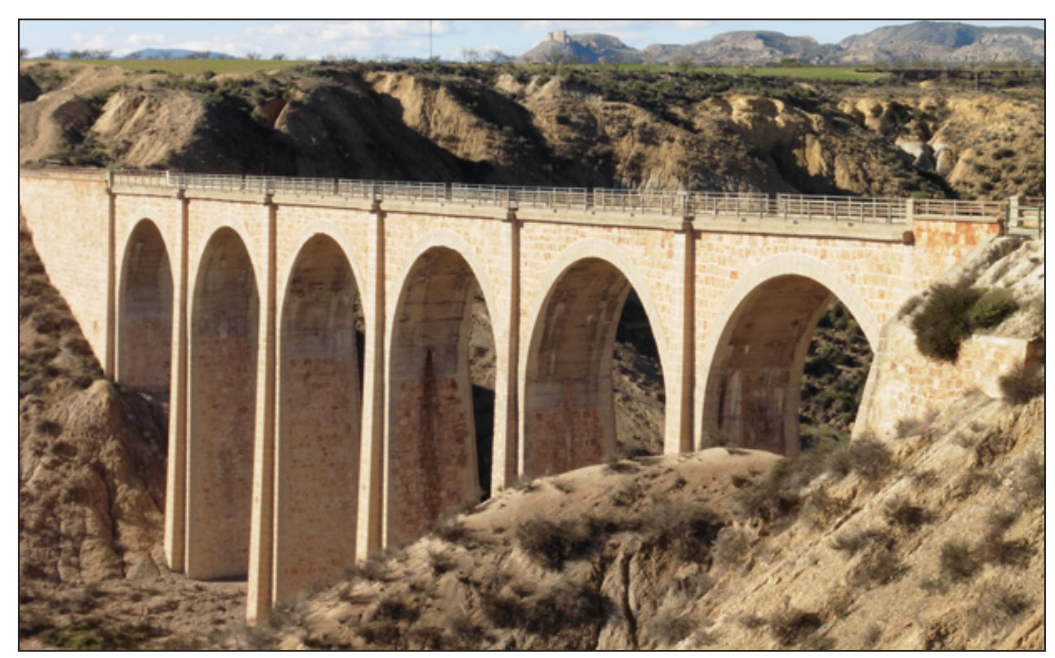

Infraestructura construida para salvar la Rambla de Perea; hoy forma parte de la Vía Verde del Noroeste, magnífico mirador para observar el paisaje. Fotografía: G. Canales Martínez.

Otra propuesta de recorrido coincide, en su primer tramo, con el anterior hasta el puente sobre el río Mula. A partir de aquí, se sigue la margen izquierda del cauce y en paralelo a la Acequia de la Huerta de Cara, se prosigue hasta el Azud de Daya, para retroceder desde allí al punto de partida. La longitud máxima no llega a dos kilómetros, si bien se trata de un itinerario más restrictivo al discurrir por propiedades privadas y presentar cierto riesgo al tener que salvar determinados barrancos caminando por el borde de la acequia, lo que requeriría previamente un acondicionamiento, además de señalización; por lo que hoy 
sólo es practicable por personas amantes de la naturaleza y con un amplio conocimiento del medio, que van buscando en él los valores y atractivos que ofrece la cuenca fluvial.

Al patrimonio natural de este trayecto hay que unir el cultural, conformado por bienes de interés etnográfico como las presas de derivación, la consiguiente red de acequias y la existencia en ellas de antiguas norias. Todo este conjunto de carácter hidráulico es vital para comprender el proceso de colonización y puesta en cultivo del valle, al ser éste de fondo plano y presentar márgenes más o menos escarpados, que hicieron necesario desde antiguo contar con estos artilugios elevadores. En concreto, en la zona descrita se pueden contemplar el Azud de Cara (15 m de longitud y 1,2 m de altura sobre el lecho) y el Azud de Daya (21,5 m de largo y $2 \mathrm{~m}$ de distancia del pie a la coronación), encontrándose en la actualidad revestidos de hormigón. De ellos parten sendas acequias homónimas que riegan 100 y 60 hectáreas respectivamente; en la primera de ellas todavía se mantienen, aunque sin uso y en un lamentable estado de conservación al quedar sustituidas por motores, las norias de Casa Llanos y del Prado, con 8 y 9 metros de diámetro cada una (y que forman parte de un conjunto de seis de estos artefactos que llegaron a funcionar en dicha canalización desde Los Baños hasta la localidad de Albudeite). Una vez elevada el agua, se conducía por gravedad mediante pequeños acueductos hacia balsas de recepción, para poner en cultivo de regadío tierras de secano que quedaban por debajo de la cota de almacenamiento. Se trata de un espacio de ocupación tradicional ya en funcionamiento según documentación a principios del siglo XVI (Montes, s/a) y que ha posibilitado la existencia de un peculiar sistema agrícola de gran interés, tanto paisajístico como didáctico.

Figura 10

\section{APEADERO FERROVIARIO DE BAÑOS DE MULA}

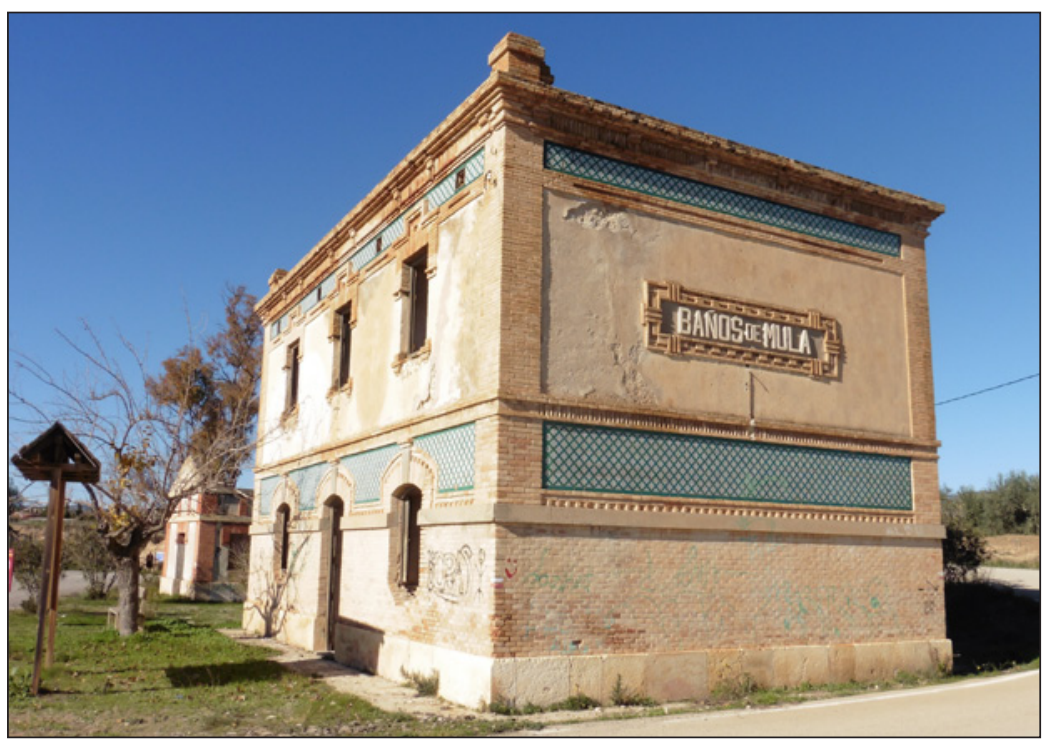

Edificación que contribuyó a dinamizar el complejo balneario a mediados del siglo XX. En la actualidad, en lamentable estado de abandono. Fotografía: G. Canales Martínez. 
c) Mejorar la capacidad de alojamiento y de promoción del conjunto termal. A pesar del cierre de establecimientos de baños ocurrido en las últimas décadas, todavía la pedanía mantiene una importante capacidad de hospedaje a nivel municipal, pues la totalidad de los apartamentos turísticos censados en la localidad, que suponen el $40 \%$ de las plazas, se ubican en el conjunto hidrotermal, como ofrece la Tabla 4. Sin embargo, el caserío carece de otras tipologías de alojamiento, por lo que sería deseable ante el número de inmuebles cerrados y en un progresivo estado de deterioro, su rehabilitación para ampliar la oferta de pernoctaciones, ya sea como hoteles, casas rurales o albergues, dado que el lugar posee un extraordinario recurso endógeno susceptible de ser convertido en un auténtico producto para el turismo. Lo ideal sería transformar el balneario en un centro renovado, adaptándolo a los nuevos tiempos en los que, sin perder su carácter intrínseco dedicado a la salud, ofrezca otros servicios relacionados con tratamientos preventivos de bienestar así como de belleza, sin olvidar las posibilidades de ocio que desde él se pueden practicar en relación con el entorno.

Tabla 4

TIPO DE ALOJAMIENTO Y CAPACIDAD EN EL MUNICIPIO DE MULA, 2017

\begin{tabular}{|l|c|c|c|}
\hline \multicolumn{1}{|c|}{ CATEGORÍA } & N. $^{{ }^{\circ}}$ ESTABLECIMIENTOS & N. $^{{ }^{\circ}}$ PLAZAS & \% \\
\hline Hotel & 3 & 64 & 23,44 \\
\hline Apartamentos Turísticos & 5 & 108 & 39,56 \\
\hline Casa Rural & 14 & 101 & 37,00 \\
\hline TOTAL & 22 & 273 & 100,00 \\
\hline
\end{tabular}

Fuente: Instituto de Turismo de la Región de Murcia.

El aumento de competitividad del enclave requiere, por lo tanto, una adecuación y ampliación de la capacidad de alojamiento incorporando otros modelos de hospedaje, sin que se desvirtúe su autenticidad y originalidad. El conjunto presenta como importante elemento de atracción el propio recinto balneario que debe de evolucionar de la actual situación de apartamentos turísticos, es decir, casa de huéspedes con derecho a baño, hacia una instalación hotelera de carácter terapéutico bajo control médico. Esto supondría una transformación de la imagen y del uso tradicional que se hace del agua; todo ello debería realizarse mediante un cambio en la gestión empresarial, que de mantener las actuales circunstancias de entrega en arriendo, éste debería de ser con contratos de media-larga duración, sin los cuales no es posible alcanzar los deseos de mejora e innovación. Por otro lado, la búsqueda de un producto diferente y complementario a la mera actividad termal supondría ampliar la proyección hacia segmentos de mercados nuevos. Es de destacar que existen factores potenciales tanto desde el lado de la demanda como desde el de la oferta; con relación al primero, en las últimas décadas ha cobrado fuerza el interés por el patrimonio y el contacto con la naturaleza para la práctica de actividades lúdico-deportivas; con relación al segundo, el pequeño núcleo rural ofrece un rico legado histórico-cultural en un incomparable marco natural de gran belleza paisajística, que no es suficientemente valorado y aprovechado en su comercialización actual. 


\section{Tabla 5 \\ CAMBIOS DE ORIENTACIÓN PARA EL MODELO TERMAL LOS BAÑOS DE MULA}

\begin{tabular}{|l|c|c|}
\hline \multicolumn{1}{|c|}{ CARACTERÍSTICAS } & SITUACIÓN ACTUAL & PROPUESTA DE FUTURO \\
\hline Estructura empresarial & Arrendamiento del hospedaje & Diversificación de los alojamientos \\
\hline Funcionamiento comercial & Individual y familiar & Ampliación de la clientela \\
\hline Uso social & Esporádico-minoritario & Continuo-sostenible \\
\hline Espacio turístico & Concentrado a pequeña escala & $\begin{array}{c}\text { Conservación del patrimonio } \\
\text { construido }\end{array}$ \\
\hline
\end{tabular}

Fuente: Elaboración propia fruto del trabajo de campo y las entrevistas realizadas.

La proyección de Los Baños de Mula conllevaría la adecuación del conjunto hidrotermal a un uso turístico de mayor alcance, pero manteniendo la esencia de su origen, tal y como refleja la Tabla 5. Esta modernización podría suponer una ampliación de su clientela mediante la diversificación de la oferta, incorporando segmentos de población hasta ahora no contemplados, como son los mayores atraídos por el binomio agua-salud, principales destinatarios del Programa de Termalismo Social desarrollado por la Dirección General del Inserso puesto en marcha en 1989; además de un público más joven motivado por la conjunción agua-ocio siempre que encuentren un alojamiento adecuado a su nivel adquisitivo; circunstancias que en ambos casos contribuirían a dinamizar el centro termal.

Figura 11

PERSPECTIVA DE LA CALLE SUPERIOR DEL BALNEARIO

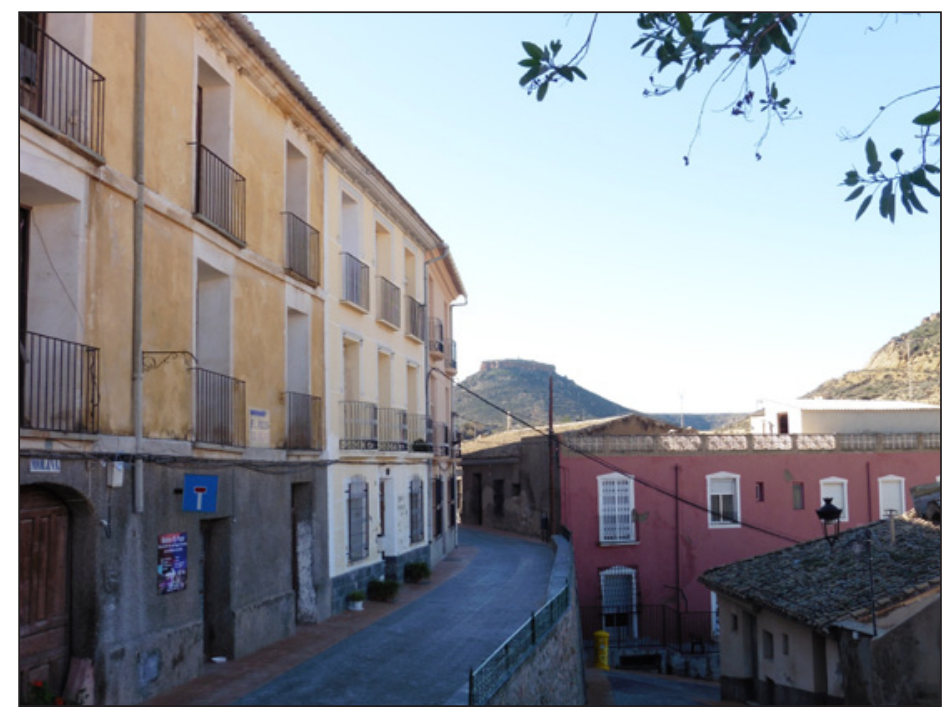

Calle Cuesta del Horno que da acceso al parador de Molina, en primer término a la izquierda; infraestructura que puede contemplarse para su adecuación como albergue rural. Al fondo, el imponente cerro de Alcalá. Fotografía: G. Canales Martínez. 
Para estos últimos, se propone la creación de un albergue juvenil (Figura 11) aprovechando alguno de los inmuebles hoy en desuso, como puede ser el Parador de Molina, circunstancia que dotaría de un nuevo servicio al caserío, así como la recuperación de un edificio representativo, cuya construcción es exponente de un tipo de inmueble con dependencias, distribuidas en dos plantas, organizadas alrededor de un gran patio central. Esta actuación redundaría en favor no sólo de la pedanía sino del propio municipio muleño, pues al aumentar la capacidad de acogida para estos grupos de menor edad, se superaría la práctica tan frecuente del excursionismo.

Asimismo, se podría contemplar la ampliación de la red de alojamiento al incorporar como casas rurales viviendas particulares con derecho al agua del manantial; de esta manera, se conservaría la unidad del complejo arquitectónico a la par que se incrementaría la oferta, dado que en la actualidad tan sólo hay censados en el municipio 14 inmuebles y ninguno de ellos se ubica en el centro hidrotermal. Dicha medida contribuiría a ampliar las plazas de hospedaje del balneario, incrementando así las existentes en el conjunto de la comarca de Mula (con un total de 20 establecimientos, 6 de ellos ubicados en Pliego), muy por debajo de la media de la Región de Murcia, incapaz de competir con otros lugares cercanos, tanto en cantidad como en calidad; este es el caso de la vecina comarca del Noroeste que reúne 338 casas rurales (Instituto de Turismo de la Región de Murcia, 2016).

No obstante, en los últimos años se han incorporado dos nuevos negocios turísticos, El Rincón de Resu y Casa Postas Morata, emplazados en el eje de acceso a Los Baños, ubicados en la antigua casa de postas, edificio rehabilitado del siglo XVIII. Se trata, en ambos casos, de infraestructuras con categoría superior a la de los paradores (Tabla 6) y que disponen también de varios apartamentos con mayor grado de confort en sus instalaciones, al ofrecer modernos servicios de piscina climatizada, spa y jacuzzi aunque sus aguas no tienen las propiedades terapéuticas que se dan en las instalaciones termales.

Tabla 6

ESTABLECIMIENTOS DE HOSPEDAJE EN LOS BAÑOS DE MULA EN 2017

\begin{tabular}{|l|c|c|c|}
\hline \multicolumn{1}{|c|}{ Parador } & Categoría (llaves) & N. $^{\mathbf{0}}$ Apartamentos & N. ${ }^{{ }^{*}}$ Plazas \\
\hline El Intendente & 1 & 9 & 40 \\
\hline Apartamentos Azul & 1 & 6 & 28 \\
\hline Delfín Rojo & 1 & 3 & 18 \\
\hline El Rincón de Resu & 2 & 4 & 8 \\
\hline Casa Postas Morata & 3 & 4 & 14 \\
\hline TOTAL & - & 26 & 108 \\
\hline
\end{tabular}

Fuente: Instituto de Turismo de la Región de Murcia.

Por último, sería deseable la comercialización conjunta de todo el recinto de Los Baños mediante la creación de un entorno web que aglutine toda la oferta turística que allí se localiza, así como las posibles actividades y visitas a realizar en sus inmediaciones. En la actualidad, los cinco negocios turísticos que hay abiertos al público dispone cada uno de su propia página web, con notables diferencias y centradas mayoritaria- 
mente en ofrecer sus instalaciones con los correspondientes apartados de servicios, tarifas, reservas, galería de fotografías y cómo llegar; si bien con escasas referencias a la historia del lugar y cuando se alude a ella, es de forma escueta. Tan sólo El Intendente señala las propiedades y beneficios de los baños termales, así como, las indicaciones para aprovechar mejor su uso. Las referencias a un complemento lúdico-recreativo en el entorno apenas destacan en ellas, así en los Apartamentos Azul únicamente se cita "un lugar repleto de opciones de ocio para disfrutar" y en otro apartado, que se encuentra con "fácil acceso y comunicaciones con los alrededores. Rodeado de naturaleza y tranquilidad", sin especificar los sitios de interés. Mayor detalle se observa en la página El Rincón de Resu, que ofrece un listado de lugares cercanos a recorrer aunque sin aportar más datos, mientras que Casa Postas Morata muestra las propuestas a desarrollar con imágenes llamativas del patrimonio natural y cultural próximo, con una breve descripción. Por el contrario, si nos atenemos a la página institucional de la administración local, ésta muestra una pobre información respecto a la evolución histórica del núcleo y solamente presenta enlaces a las respectivas webs de los paradores. Para dar una mayor proyección al entorno, se considera pertinente la puesta en marcha de un dominio digital que ofrezca las peculiaridades globales de la citada pedanía, con un contenido atractivo y amplio de sus principales características y con vínculos a los distintos recursos locales, que hagan atrayente el lugar como destino turístico de interior para una población que hoy desconoce la singularidad de este territorio.

\section{CONCLUSIONES}

La pedanía muleña de Los Baños, organizada desde hace tres siglos en torno al aprovechamiento de una surgencia mineromedicinal, con una peculiar distribución en varios establecimientos y un uso decreciente de sus instalaciones termales, presenta a día de hoy una situación social y económica en claro declive, escasos habitantes y pocas posibilidades laborales. Entre las principales causas de esta situación está el tipo de gestión de los paradores y casas de baño, que son explotados en régimen de arrendamiento, pero en ningún modo pueden competir con los balnearios capitalizados o los nuevos desarrollos hoteleros con spa, cuyo nivel de equipamiento y servicios es mucho más elevado. A esta situación de decadencia se suma la mejora y adecuación de las vías de comunicación que hoy permiten la conexión rápida con otros puntos que unen al disfrute del agua otras prestaciones relacionadas con el ocio, cultura, naturaleza o patrimonio, lo cual reduce aún más si cabe, la atracción turística del lugar. De ahí que el conjunto hidrotermal de Mula sea frecuentado únicamente por una clientela que, aunque aprecia la calidad y propiedad terapéutica del recurso, apenas pernocta en el lugar y sólo lo utiliza temporal y esporádicamente por horas, circunstancia que contribuye a su estancamiento actual.

Para considerar una recuperación de este territorio y aprovechar el potencial de su patrimonio arqueológico, hidráulico y etnográfico, sería necesario un plan de actuación con medidas como las que aquí se plantean, encaminadas hacia un turismo sostenido que apoye los valores constructivos, así como el posible uso didáctico y educativo a desarrollar. El logro dependerá de la participación de todos los actores sociales, comenzando por una clara determinación de la población residente y propietaria del agua, junto con 
la administración local. Como se ha expuesto, será necesaria la adecuación de las termas y el aumento de los servicios ofertados; la adaptación de algunas infraestructuras a otros usos y la creación de itinerarios que pongan en valor y muestren los recursos naturales y culturales allí reunidos, para captar así a todo tipo de visitantes, sobre todo aquellos de ámbito regional y nacional que desconocen las formidables cualidades salutíferas del manantial como el potencial paisajístico de sus alrededores. En este cometido de carácter integral, es básico el papel que deben desempeñar los organismos públicos y privados para rescatar del deterioro Los Baños de Mula y su entorno, siempre que sean capaces de aunar esfuerzos, en aras de hacer de este enclave un referente patrimonial suficientemente conocido y disfrutado por todos.

\section{BIBLIOGRAFÍA}

ANDRÉS SARASA, J. L. (2000): «Aportaciones básicas del turismo al desarrollo rural», Cuadernos de Turismo, $\mathrm{n}^{\circ}$ 6, pp. 45-59.

ARCHIVO MUNICIPAL DE MULA (AMM). Legajo 13. Tomo II.

AYUNTAMIENTO DE MULA (1993). Estudio informativo de los Baños de Mula y propuestas para su promoción y desarrollo turístico.

BOE. Ley 4/2007, de 16 de marzo, de Patrimonio Cultural de la Comunidad Autónoma de la Región de Murcia, $\mathrm{n}^{\circ}$ 176, de 22 de julio de 2008.

BOE. Ley 13/1985, de 25 de junio, de Patrimonio Histórico Español.

CARAVACA PÉREZ, A. (1976): El Pajal. Ediciones 23/27. Murcia.

ESPEJO MARÍN, C. (1997): «La oferta de turismo rural en el Noroeste de la Región de Murcia», Geographicalia, no 35, pp. 87-97.

GALIANA, I. y FERNÁNDEZ, A. (1977): Guía secreta de Murcia, Cartagena y Mar Menor. Madrid. Ed. Sedmay.

GARCÍA SAMPER, M. (2017): La obra escultórica de Sánchez Lozano en la Hermandad de Nuestra Señora del Carmen de la Ciudad de Mula. Mula. Ayuntamiento de Mula.

GÓMEZ ESPÍN, J.M., LÓPEZ FERNÁNDEZ, J.A. y MONTANER SALAS, M.E. (2011): Modernización de regadios: sostenibilidad social y económica. La singularidad de los regadios del Trasvase Tajo-Segura. Murcia. Servicio de Publicaciones. Universidad de Murcia.

GONZÁLEZ CASTAÑO, J. y GONZÁLEZ FERNÁNDEZ, R. (1996): Aproximación a la historia de Los Baños de Mula. Mula. Ayuntamiento de Mula.

GONZÁLEZ CASTAÑO, J. (1995): El Niño Jesús de Mula: estudio histórico y antropológico de una devoción murciana. Mula. Imprenta "La Muleña".

GONZÁLEZ CASTAÑO, J. (1994): Origen y desarrollo de la tamborada de la ciudad de Mula (Murcia). Mula. Asociación de tamboristas de Mula.

GONZÁLEZ CASTAÑO, J. (1992): Una villa en el Reino de Murcia en la Edad Moderna (Mula, 1500-1648). Academia Alfonso X El Sabio, Murcia.

GONZÁLEZ FERNÁNDEZ, R., FERNÁNDEZ MATALLANA, F. (2002). «Prospección y trabajos arqueológicos en el cerro de La Almagra (Mula, Murcia)», Memorias de Arqueología, no 11, pp. 331-338. 
GONZÁLEZ FERNÁNDEZ, R. y FERNÁNDEZ MATALLANA, F. (1997): «El Cerro de La Almagra: Mula, ciudad del Pacto de Teodomiro», Actas del I Congreso Internacional "Ciudades Vivas, Ciudades del Pasado", Mérida, pp. 33-36.

GONZÁLEZ, R., FERNÁNDEZ, F. y CRESPO, M. (1997): «La cerámica tardía realizada a mano hallada en superficie en el cerro de la Almagra (Mula, Murcia). Campaña de 1996». Antigüedad y Cristianismo, n 14, pp. 619-641

INSTITUTO DE TURISMO DE LA REGIÓN DE MURCIA (2016): Listado de ofertas de alojamiento de casas rurales de alquiler, a fecha 30/06/2016. Consejería de Desarrollo Económico, Turismo y Empleo. Comunidad Autónoma de la Región de Murcia.

JARRASSÉ, D. (2002): «La importancia del termalismo en el nacimiento y desarrollo del turismo en Europa en el siglo XIX». Historia Contemporánea, n 25, pp. 33-49.

JIMÉNEZ LANDÍ, A. (1984): «Las excursiones de la Institución». Estudios Turísticos, $\mathrm{n}^{\circ} 83$, pp. 101-108.

JIMÉNEZ LANDÍ, A. (1996): La Institución Libre de Enseñanza. III. Periodo escolar. 1881-1907. Madrid. Ministerio de Educación y Cultura.

LARRUBIA VARGAS, R. y LUQUE GIL, A.M. (2002): «Las estaciones termales en Andalucía: de la explotación tradicional a la configuración de un nuevo producto turístico integral». Cuadernos de Turismo, n 10, pp. 101-122.

LAVERDAD.ES. (2016): Los regantes de Baños de Mula y Albudeite piden «amparo» a la Asamblea ante la Confederación Hidrográfica del Segura. Edición Murcia, 7 de noviembre de 2016.

LILLO CARPIO, M.J. y HERNÁNDEZ HUESCAR, J.M. (2007): «Interés de noticias y datos históricos para la interpretación geomorfológica del paisaje de los Baños de Mula», en Historia y Sociabilidad: Homenaje a la profesora María del Carmen Melendreras Gimeno, (Vilar, Peñafiel e Irigoyen, Coords.). Universidad de Murcia, pp. $149-170$

LILLO CARPIO, M.J. (2005): «De viajeros a turistas: consideraciones sobre los tradicionales desplazamientos a los baños naturales murcianos», en Libro de viaje y viajeros en la literatura y en la Historia (Carmona y García, Eds.). Universidad de Murcia, pp. 189-234.

LILLO CARPIO, M.J. y LISÓN HERNÁNDEZ, L. (2003): Los aprovechamientos termales en Archena. Murcia. Universidad de Murcia.

LILLO CARPIO, M.J. y LISÓN, HERNÁNDEZ, L. (2002): Los aprovechamientos termales en Fortuna. Murcia. Universidad de Murcia.

LOPES BRENNER, E. (2005): «El desarrollo turístico de las estaciones de aguas termales de Goiás, Brasil». Cuadernos de Turismo, n ${ }^{\circ}$ 16, pp. 105-121.

LÓPEZ, E. (1995): «Mula en el Tratado de Tudmir (s. VIII)». Aproximación al estudio de Mula islámica, Murcia, pp. 25-32.

LÓPEZ, J. A. (2014): Actuaciones de desarrollo rural y local en la comarca de Mula. Región de Murcia. 1980-2010. Análisis, perspectivas y propuestas. Mula.

MADOZ, P. (1848): "Mula (Baños de)". Diccionario geográfico-estadístico-histórico de España y sus posesiones de ultramar. Est. Literario-Tipográfico de P. Madoz y L. Sagasti. 
MARRÓN GAITE, M.J. (1990): «El entorno como objeto de estudio y como recurso didáctico para la enseñanza de las Ciencias Sociales en EGB. Una experiencia de trabajo para el estudio activo del entorno rural», Didáctica (Lengua y Literatura), $\mathrm{n}^{\circ}$ 2, pp. 161-170.

MILLAN ESCRICHE, M. (2004): «Ocio y turismo en la Región de Murcia. Alternativas para su diversificación», Cuadernos de Turismo, $\mathrm{n}^{\circ}$ 14, pp. 13-177.

MONTES BERNARDEZ, R. (s/a): Historia de Albudeite. Ayuntamiento de Albudeite. $168 \mathrm{pp}$.

PANIAGUA, J.I. y MARTíNEZ, M. (2003): Panorama actual de las Aguas Minerales y Minero-medicinales en España. Instituto Geológico y Minero de España. Ministerio de Ciencia y Tecnología.

PIÑEIRO, M.R. (1983): «El entorno y su valor pedagógico», Aula Abierta, nº 38, pp. 79-87.

PLAN DE GESTIÓN DE LA ZONA ESPECIAL DE CONSERVACIÓN “RÍO MULA Y PLIEGO”. Dirección General de Medio Ambiente. Comunidad Autónoma de la Región de Murcia. 128 pp. 